\title{
SNOW DEPTH DISTRIBUTION PATTERNS AND \\ CONSISTENCY FROM AIRBORNE LIDAR TIME SERIES
}

by

Megan A. Mason

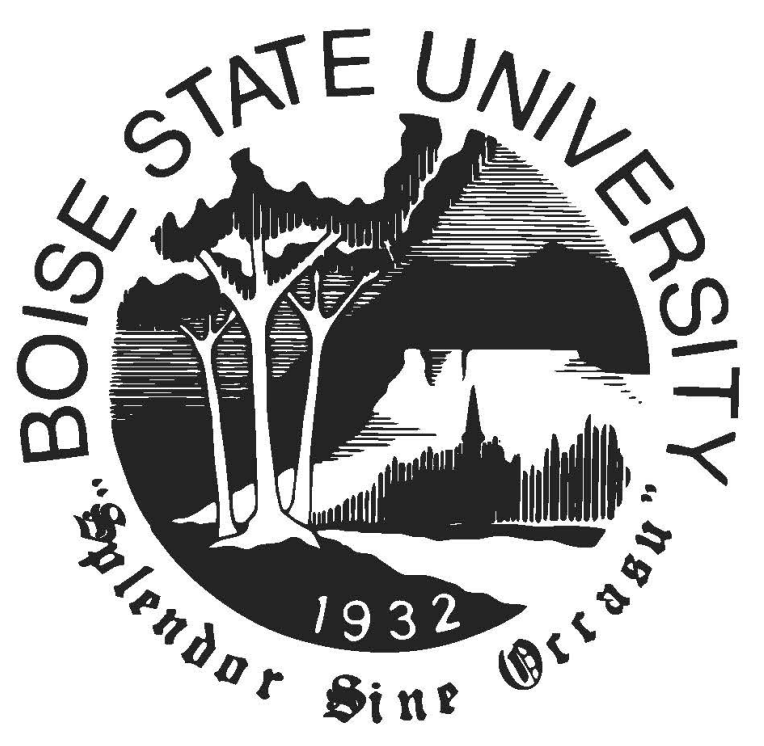

\author{
A thesis \\ submitted in partial fulfillment \\ of the requirements for the degree of \\ Master of Science in Geophysics \\ Boise State University
}

August 2020 
(C) 2020

Megan A. Mason

ALL RIGHTS RESERVED 
BOISE STATE UNIVERSITY GRADUATE COLLEGE

\title{
DEFENSE COMMITTEE AND FINAL READING APPROVALS
}

\author{
of the thesis submitted by
}

\author{
Megan A. Mason
}

Thesis Title: Snow Depth Distribution Patterns and Consistency from Airborne Lidar Time Series

Date of Final Oral Examination: 26 June 2020

The following individuals read and discussed the thesis submitted by student Megan A. Mason, and they evaluated the student's presentation and response to questions during the final oral examination. They found that the student passed the final oral examination.

Hans-Peter Marshall Ph.D. Chair, Supervisory Committee

Nancy F. Glenn Ph.D. Member, Supervisory Committee

Ernesto Trujillo Ph.D. Member, Supervisory Committee

The final reading approval of the thesis was granted by Hans-Peter Marshall Ph.D., Chair of the Supervisory Committee. The thesis was approved by the Graduate College. 


\section{ACKNOWLEDGMENT}

I would like to thank my advisor, Dr. Hans-Peter (HP) Marshall, for his continued support every step of the way. HP, you are an outstanding professor and will continue to be my mentor in my future chapters. I am so grateful for the field and workshop opportunities you supported and encouraged. I felt both challenged and proud during the course of my Masters program, and left in awe at your ability to constantly provide solutions no matter how big or small the matter. To my other two committee members, Dr. Nancy Glenn and Dr. Ernesto Trujillo, thank you for your time, feedback, and unwavering support. Your expertise were very much appreciated and helped me grow.

This research was heavily bolstered by the entire staff at USDA-ARS (the 'snow modeling crew'). Thank you very much for your support and lessons in programming.

Thank you to the dataset providers, whether it was the ground-based observation crew at Grand Mesa or the hours spent processing lidar data over the high country of Tuolumne. Both datasets are unprecedented for spatio-temporal snow observations and I was fortunate to have them both at the core of my research.

And lastly, to the graduate and life long friends I made while on this endeavor - whether our time together was short or long, you undoubtedly made a significant impact that I will carry with me. 


\section{ABSTRACT}

Snow provides fresh meltwater to over a billion people worldwide. Snow dominated watersheds drive western US water supply and are increasingly important as demand depletes reservoir and groundwater recharge capabilities. This motivates our interand intra-annual investigation of snow distribution patterns, leveraging the most comprehensive airborne lidar survey (ALS) dataset for snow. Validation results for ALS from both the NASA SnowEx 2017 campaign in Grand Mesa, Colorado and the time series dataset from the Tuolumne River Basin in the Sierra Nevada, in California, are presented. We then assess the consistency in the snow depth patterns for the entire basin (at 20-m resolution) and for subbasin regions (at 3-m resolution) from a collection of 51 ALS that span a six-year period (2013-2018) in the Tuolumne Basin. Strong correlations between ALS from different years near peak SWE confirm that spatial patterns exist between snow seasons. Year-to-year snow depth differs in abso-

lute magnitude, but relative differences are consistent spatially, such that deep and shallow zones occur in the same location. We further show that elevation is the terrain parameter with the largest correlation to snow depth at the basin scale, and we map the expected pattern distribution for periods with similar snow-covered extents. Lastly, we show at a subbasin scale that distribution patterns are more consistent in vegetation-limited areas (bedrock dominated terrain and open meadows) compared to vegetation-rich zones (valley hillslopes and dense canopy cover). The maps of snow 
patterns and their consistency can be used to determine optimal locations of new long-term monitoring sites, design sampling strategies for future snow surveys, and to improve high resolution snow models. 


\section{TABLE OF CONTENTS}

ACKNOWLEDGMENT . . . . . . . . . . . . . . . . iv

$\mathrm{ABSTRACT} \ldots \ldots \ldots \ldots \ldots \ldots \ldots$

LIST OF FIGURES . . . . . . . . . . . . . . . . . .

LIST OF TABLES ........................ xiv

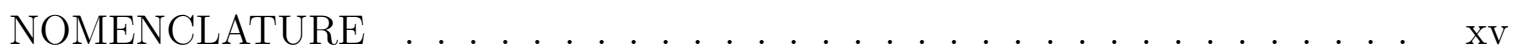

1 AIRBORNE LIDAR SURVEY (ALS) RELEVANCE AND ACCURACY FOR SNOW DEPTH MEASUREMENTS . . . . . . . . . . . . . . . 1

1.1 Introduction . . . . . . . . . . . . . . . . 1

1.2 Study Area . . . . . . . . . . . . . . . . . . . . 3

1.2.1 Grand Mesa, Colorado . . . . . . . . . . . . . . 3

1.2.2 Tuolumne Basin, California . . . . . . . . . . . . . 3

1.3 Background and Methodology ................ 5

1.3.1 History of Lidar . . . . . . . . . . . . . . . . . . . 5

1.3.2 Datasets: Airborne Lidar Survey (ALS) and Ground-based Validation .......................... 6

1.3.3 Hydrologic Application of Basin Scale Studies . . . . . . . . . 8 
1.3.4 Errors and Uncertainties of Lidar . . . . . . . . . . . . . . 9

1.3.5 Data Preparation ... . . . . . . . . . . . . . 11

1.4 Results . . . . . . . . . . . . . . . . . . . 13

1.5 Discussion . . . . . . . . . . . . . . . . . . . 18

1.6 Conclusion . . . . . . . . . . . . . . . . . . . . . . 19

2 WHOLE BASIN TRENDS IN A MULTI-YEAR HIGH RESOLUTION AIRBORNE LIDAR SNOW DEPTH DATASET . . . . . . . . . . . . . 21

2.1 Introduction . . . . . . . . . . . . . . . . . . . . . 21

2.2 Study Area . . . . . . . . . . . . . . . . . . . . . . . 23

2.3 Background and Methodology . . . . . . . . . . . . 25

2.3.1 Airborne Lidar Survey (ALS) Dataset . . . . . . . . . . . 25

2.3.2 Inter-Annual Correlation . . . . . . . . . . . . . . . . . . 27

2.3.3 Empirical Cumulative Distribution Function (ECDF) . . . . . 28

2.3.4 ALS Selection for ECDF Analysis . . . . . . . . . . . . 31

2.3.5 Random Forest Classifier . . . . . . . . . . . . . . . . . . . 32

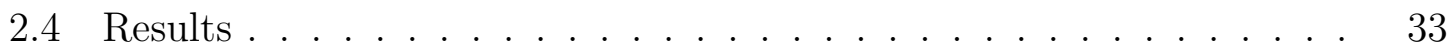

2.4.1 Inter-Annual Correlation . . . . . . . . . . . . . . . 33

2.4.2 Empirical Cumulative Distribution Function (ECDF) . . . . . 34

2.4.3 Terrain Parameters ................ 43

2.5 Discussion . . . . . . . . . . . . . . . . . . . 45

2.5.1 Inter-Annual Correlation . . . . . . . . . . . . . . 45

2.5.2 Dataset Selection for ECDF Analysis . . . . . . . . . . . 46

2.5.3 Application of Snow Distribution Patterns and Pattern Consistency Maps . . . . . . . . . . . . . . . . . . 47 
2.5.4 Terrain Parameters . . . . . . . . . . . . . . . . 47

2.6 Conclusion . . . . . . . . . . . . . . . . . . . . . . 49

3 LOCAL DEVIATIONS FROM MEAN SNOW DEPTH AT THE SUBBASIN SCALE: VISUALIZING INTER- AND INTRA-ANNUAL PATTERNS 50

3.1 Introduction . . . . . . . . . . . . . . . . . 50

3.2 Study Area . . . . . . . . . . . . . . . . . . . . 52

3.3 Background and Methodology . . . . . . . . . . . . . 55

3.4 Results . . . . . . . . . . . . . . . . . 56

3.4.1 Inter-Annual at Dana Meadows . . . . . . . . . . . 56

3.4.2 Intra-annual at Acker Peak and Meadow . . . . . . . . . . . . 57

3.5 Discussion . . . . . . . . . . . . . . . . . . 62

3.5.1 Inter-Annual at Dana Meadows . . . . . . . . . . . . . . . 63

3.5.2 Intra-Annual at Acker Peak and Meadow . . . . . . . . . . . . 64

3.6 Conclusion . . . . . . . . . . . . . . . . 65

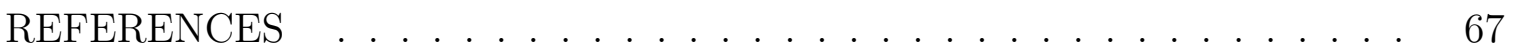

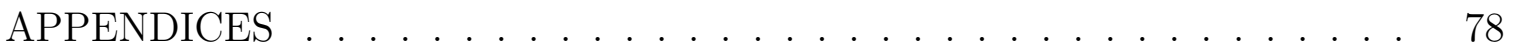

A KERNEL SIZE EVALUATION FOR LOCAL MEAN ANALYSIS $\quad \ldots .79$ 


\section{LIST OF FIGURES}

1.1 Geographic location for Airborne Lidar Survey (ALS) validation sites. Grand Mesa, Colorado $\left(100+\mathrm{km}^{2}\right)$ and Tuolumne River Basin $\left(1,000+\mathrm{km}^{2}\right)$ in the Sierra Nevada Mountain Range, California. . . . . . . . . . . 4

1.2 Single ALS at each site. (A) Grand Mesa, CO on 8 February 2017 and

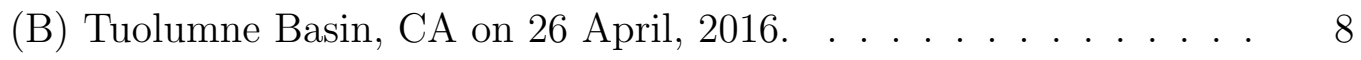

1.3 Lidar window size optimization. Lowest RMSD (y-axis, left) and highest correlation coefficient (y-axis, right) were determined to optimize overlapping lidar selection to snow-probe transect point. . . . . . .

1.4 Kernel probability density function (PDF) for ground-based and airborne lidar survey observations. . . . . . . . . . . . . . . . . 14

1.5 Comparison of ALS with ground-based snow-probe transect observations. Points are categorized by forest $(\geq 5 \mathrm{~m})$ and open $(<5 \mathrm{~m})$. (top left) ALS date is 8 Feb, snow-probe 7-10 Feb. (top right) ALS date is 25 Feb, snow-probe 21-25. (bottom) Difference between snow-probe measurement and overlapping ALS measurement. . . . . . . . . .

1.6 ALS temporal validation with three metrological sites (A) Dana Meadows (blue), (B) Tuolumne Meadows (red), (C) Slide Canyon (green). 
2.1 Digital elevation model (DEM) for the Tuolumne Basin study site. The Tuolumne Basin is located in the Sierra Nevada Mountain Range in eastern California. . . . . . . . . . . . . . . .

2.2 Spatial coverage from one of 51 ALS snow depth maps of Tuolumne Basin, in the Sierra Nevada mountain range in Eastern, California. . .

2.3 (A) Mean snow depth values for the whole basin. Each ALS occurrence is marked (blue points) and connected (dashed blue line) by season. Labeled dates mark the maximum basin-wide mean snow depth. (B) Percent snow covered area $(\mathrm{SCA}) \ldots \ldots \ldots \ldots$

2.4 Snow depth distribution plotted by year for all ALS in the Tuolumne Basin. Color scheme shows first to last ALS by time. For most years the first flight was near peak SWE timing in the basin. Snow depth distribution is not normally distributed . . . . . . . . . . . .

2.5 One-to-one correlation for each year with correlation value $(r)$. The two years with the greatest correlation are 2016 verse $2017(r=0.89)$, and the lowest correlation are 2015 verse $2017(r=0.66)$, the two most different snow years is recent history. . . . . . . . . . . . .

2.6 (A). Mean of the ECDF for 21 ALS with $80 \%$ and greater SCA. (B). 21 ECDFs of snow depth for the whole basin. (C) Close up of ECDF values from the mean ECDF (black extent box in A). Gray polygons are alpine lakes. . . . . . . . . . . . . . . . 
2.7 (A). Mean of the ECDF for 6 ALS nearest peak SWE. (B). 6 Empirical CDFs of snow depth for the whole basin. (C) Close up of ECDF values from the mean ECDF (black extent box in A). Gray polygons are alpine

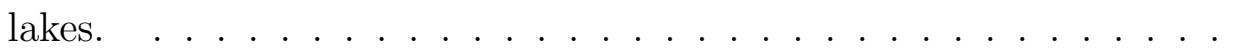

2.8 (A). Range (maximum - minimum) of the ECDF for 21 ALS with $80 \%$ and greater SCA. (B). 21 Empirical CDFs of snow depth for the whole basin. (C) Close up of ECDF values from the range of ECDF (black extent box in A). Gray polygons are alpine lakes. . . . . . . . . . .

2.9 (A). Range (maximum - minimum) of the ECDF for 6 ALS nearest peak SWE. (B). 6 Empirical CDFs of snow depth for the whole basin. (C) Close up of ECDF values from the range of ECDF (black extent box in A). Gray polygons are alpine lakes. . . . . . . . . . . . . .

2.106 ALS nearest peak SWE for an inter-annual comparison. Gray polygons are alpine lakes. (A). Mean of ECDFs show snow distribution patterns (B) Range of ECDFs show pattern consistency. . . . . . .

2.11 2-D Gaussian Kernel Density Estimate (KDE) for teach terrain parameter (elevation, aspect, and slope) with the mean and range ECDF results for 6 ALS nearest peak SWE. The marginal axes (top and right) plot each respective KDE to see the individual distribution of the vari-

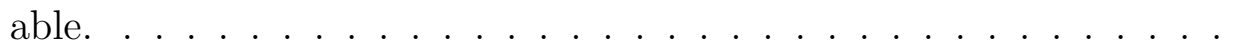

3.1 (A) Dana Meadows $\left(1-\mathrm{km}^{2}\right)$ on the east side of Tuolumne Basin with a mean elevation of 2,290 m. (B) 3-m Snow Depth product from single ALS, 26 April 2016 (one of fifty-one). (C) Vegetation height in meadow and canopy. (D) Aspect where slope is $\geq 20^{\circ}$. (E) Slopes $>20^{\circ}$. . . . 
3.2 (A) Acker Peak and Meadow $\left(3-\mathrm{km}^{2}\right)$ in the north of Tuolumne Basin with an elevation span of 2800-3200 m. (B) 3-m snow depth product from a single ALS, 26 April 2016 (one of fifty-one). (C) Vegetation height, constrained to hillslopes. (D) Aspect where slope is $\geq 20^{\circ}$. (E) Slopes $>20^{\circ} \ldots \ldots \ldots \ldots \ldots \ldots \ldots$

3.3 Dana Meadows local mean analysis. (A) ALS snow depth at 3-m resolution. One ALS per year (2013-2018) nearest peak SWE timing. (B) Local mean snow depth generated by convolution of $150-\mathrm{m}$ moving Gaussian filter. (C) Difference of A and B, or the residual snow depth

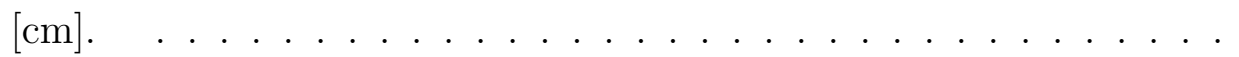

3.4 Acker Peak and Meadow local mean analysis. (A) ALS snow depth at 3-m resolution. ALS are from 2016 and cover April-June, intra-annual. (B) Local mean snow depth generated by convolution of 150-m moving Gaussian filter. (C) Difference of A and B, or the residual snow depth $[\mathrm{cm}] \ldots \ldots \ldots \ldots \ldots \ldots \ldots \ldots$

3.5 Close up of inter-annual residual snow depth patterns for the three most dissimilar snow years, 2015 (low), 2016 (near average), 2017 (high) in recent history. . . . . . . . . . . . . . . .

3.6 Close up of intra-annual residual snow depth patterns for the accumu-

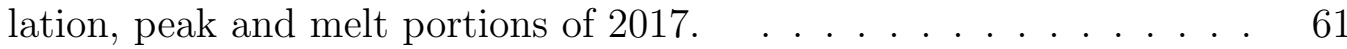

A.1 Local mean analysis evaluated with a 30-m Gaussian kernel . . . . . 81

A.2 Local mean analysis evaluated with a 150-m Gaussian kernel . . . . 82

A.3 Local mean analysis evaluated with a 500-m Gaussian kernel . . . 83 


\section{LIST OF TABLES}

1.1 Summary results for ALS and snow-probe transects. RMSD=root mean square difference, $R=$ correlation coefficient . . . . . . . . 15

2.1 Count and temporal span of ALSO dataset . . . . . . . . . . . 25

2.2 Random Forest Classifier (RFC) results. Maximum tree depth=20 . . 45 


\title{
NOMENCLATURE
}

\author{
SDV Standardized Depth Values \\ $\mu \quad$ mean \\ $\sigma \quad$ standard deviation
}




\section{CHAPTER 1:}

\section{AIRBORNE LIDAR SURVEY (ALS) RELEVANCE AND ACCURACY FOR SNOW DEPTH MEASUREMENTS}

\subsection{Introduction}

The climate in the mountainous western US is known for its historical extremes, experiencing periods of severe drought, where water reserves reach record deficits, contrasted by surfeit wet periods. In many examples, natural ecosystems are adept at navigating these climate fluxes through strategies that improve functional properties such as the root system of a plant or leaf area size to store or purge water and nutrients (Baldocchi et al., 2019). From decades of multi-disciplinary research endeavors, geoscientists continually work to better represent the physical laws that govern Earth's processes, so that we are able to estimate natural resource quantities. Of particular interest is the overwhelming need to quantify water due to its role in our ecosystem, the fact that it is vital to human life, and its sensitivity to climate change (Baldocchi et al., 2019).

In order to quantify available water, we must look to Earth's terrestrial snowcovered regions, where snowmelt produces water for one sixth of the world's popu- 
lation (Barnett et al., 2005). It's estimated that $70 \%$ of the water in the western US originates as snow and is stored seasonally via dams (Sturm et al., 2017). The dam infrastructure, along with the network of meteorological sites run by the USDANational Resource Conservation Service (NRCS), and regional modeling capabilities, are used operationally for water management. Steady progress in tracking snow depth has been made in the field of remote sensing, which offers the ability to map depth at meter resolution over large basins (Deems \& Painter, 2006).

This manuscript - in three chapters - contributes results that will aid high-resolution model development to forecast water volume and snowmelt timing at the watershed scale, the most useful scale for regional water managers. Quantifying snow depth patterns and their consistency also provides a tool for determining optimal sites for long term monitoring, and snow survey design. Here we investigate the spatial patterns of snow depth with a time series of airborne snow depth observations from Tuolumne River Basin. This basin, and others in the Sierra Nevada in California, face water scarcity and intense competition of water resources from a diverse set of stakeholders.

We begin this chapter with a brief history of Light Detection and Ranging (lidar) technology and its use within the snow community. We then discuss the hydrologic relevance of lidar snow depth observations at the basin scale and report the known errors and variability of those errors. Lastly, we present our results in combination with recent studies to validate the spatial and temporal components of the airborne lidar snow depth products made available by the Airborne Snow Observatory (ASO). The first study focuses on the spatial validation of ALS using the 2017 NASA SnowEx campaign in Grand Mesa, Colorado, while the second investigates temporal trends of the airborne lidar snow depth products of the Tuolumne Basin in eastern California. 
As a technical resource, we include a description of the open source methods used to handle the ALS snow depth products used here and in subsequent chapters.

To summarize, chapter one provides background and the current state of airborne lidar surveys (ALS) for snow purposes, followed by chapter two: snow distribution pattern trends for the whole Tuolumne Basin (20-m ALS) and chapter three: inter- and intra-annual residual snow depth patterns sub 150-m in sub regions of the Tuolumne Basin (3-m ALS).

\section{$1.2 \quad$ Study Area}

\subsubsection{Grand Mesa, Colorado}

Grand Mesa, CO was the primary site for the inaugural SnowEx campaign in 2017

(Figure 1.1). SnowEx is a multi-year NASA funded campaign effort designed to target the snow community's leading question - how much water is stored in Earth's terrestrial snow-covered region? (Brucker et al., 2017). In order to address this question, Grand Mesa, Earth's largest flat-topped mountain, was selected for its alpine environment at $3050 \mathrm{~m}$ with simple topography and vegetation gradient across the mesa. Land cover on the mesa consists of grass and shrubs and transitions to tree islands and larger closed-canopy forests to the east.

\subsubsection{Tuolumne Basin, California}

The Tuolumne Basin is a widely-studied basin for hydrologic purposes (Figure 1.1). The Tuolumne River and its tributaries are the main source of water for over two million people in the San Francisco Bay Area, and the basin is largely protected and managed by Yosemite National Park. The basin has a wide range of elevations (1150 - $4000 \mathrm{~m})$ and is characterized as a large mountain basin $\left(1000+\mathrm{km}^{2}\right)$ with steep 
gradients in air temperature and a mix of precipitation types (Zhang et al., 2017). The basin also has a mix of land cover types; the lower elevations have dense conifer forests, herbaceous meadow vegetation in the mid elevations, and exposed bedrock at the upper elevations (Cristea et al., 2014). The basin is a snow-dominated system where the majority of the precipitation input occurs during the winter months and is stored as snow until the melt season when streamflow peaks. Modeling the hydrologic response system here is simplified as a result of the predominantly granite bedrock, which minimizes melt losses to groundwater (Lundquist et al., 2016).

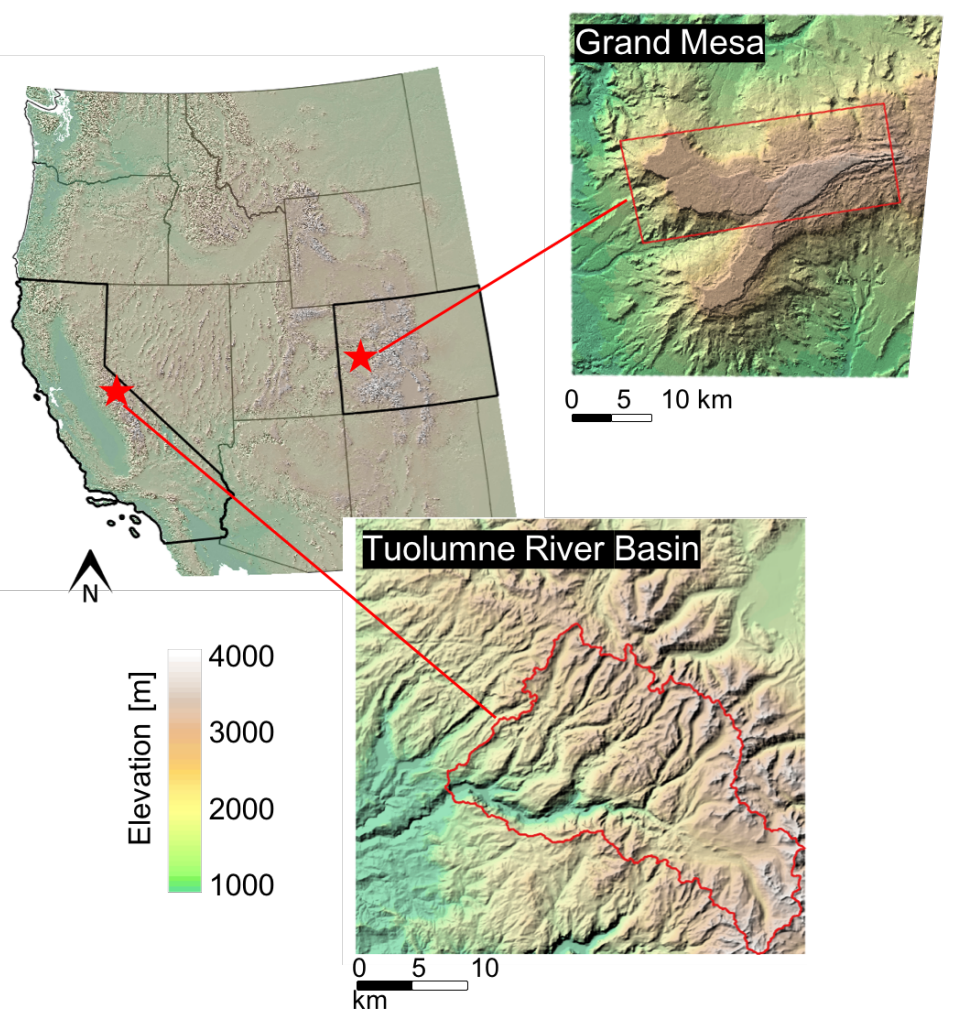

Figure 1.1: Geographic location for Airborne Lidar Survey (ALS) validation sites. Grand Mesa, Colorado $\left(100+\mathrm{km}^{2}\right)$ and Tuolumne River Basin $\left(1,000+\mathrm{km}^{2}\right)$ in the Sierra Nevada Mountain Range, California. 


\subsection{Background and Methodology}

\subsubsection{History of Lidar}

Shortly after the invention of the laser, Light Detection and Ranging (lidar) made a practical appearance for satellite distance tracking and terrestrial military targeting. Lidar had initial applications in meteorology to measure clouds and pollution, but became known to the general public in the 1970's when a laser altimeter mapped the surface during the of the Apollo 15 mission (Kaula et al., 1973). Lidar has high resolution and high accuracy; the technique is based on measurement of pulsed light waves, used to record the travel time between the source and receiver. Technical advances in data storage, and increased precision of global positioning system (GPS) receivers and inertial measurement units (IMU) in the 1980's made lidar a practical means to measure large geographical areas and produce high resolution digital elevation models (DEM) (Ackermann, 1999). Vertical accuracy increases when the distance between two objects is decreased and measurement density is high (Hopkinson et al., 2001). The most recent improvement in lidar technology allows the system to collect and store the full-waveform lidar response. This method records discrete samples of the entire back-scattered illumination beam instead of a single discrete return per sample (Deems et al., 2013).

The snow community recognized lidar technology, henceforth referred to as airborne lidar survey(s) (ALS), as the most mature technique for measuring snow depths over Earth's snow-covered terrain. Snow depth maps are feasible by conducting an airborne lidar scan during a snow-free period and again during a snow-covered period. Differencing the two DEM products results in a map of snow depths. ALS snow 
depths have much higher resolution than a typical manual snow depth survey, and can cover much larger areas than terrestrial laser scans (TLS). The Airborne Snow Observatory (ASO) is one of a few organizations that specializes in snow depth products (Painter et al., 2016). ASO has flown a number of sites in the western US; two of these sites that contain coincident snow depth measurements were selected in this study to highlight the relevancy and uncertainties of airborne snow depth mapping.

\subsubsection{Datasets: Airborne Lidar Survey (ALS) and Ground- based Validation}

\section{Grand Mesa}

The 2017 NASA SnowEx campaign in Grand Mesa, CO has the most comprehensive ground truthing dataset in which to evaluate ALS. Manual snow depths were collected via snow probe measurements in north-south and east-west transects. A collection of $17,000+$ measurements make up the dataset, and were collected over the course of a three-week period. Two ALS from the first and third campaign week, 8 and 25 February, respectively are used with the coincident manual snow depth measurements that temporally align during the periods of Feb. 7-10 and Feb. 21-25, respectively. The two ALS scenes have 1-m resolution and cover $\sim 25 \mathrm{~km}$ east-west swath across the mesa (Painter, 2018a) (Figure 2.2a). The estimated vertical uncertainty for manual snow depth measurements is $\pm 5 \mathrm{~cm}$ from the possibility of sampling into the soil beneath the snow, probing woody shrubs, or inserting the probe at an angle (Currier et al., 2019). The location error of the snow-probe transects is estimated at better than $\pm 5 \mathrm{~m}$ because transect end points were geolocated to $\mathrm{cm}$ accuracy and each 3-m

sample distance was marked off with the probe; locations are therefore more accurate 
near the end points.

\section{Tuolumne Basin}

The most comprehensive ALS dataset to date is over the Tuolumne River Basin, where full coverage ALS is available starting in 2013 and continuing to the present (Figure 2.2b). For this study, 51 fully-distributed 3-m ALS from 2013-2018 were available (Painter, 2018b). This unprecedented collection of ALS provides a temporal component to a rich spatial dataset. The majority of ALS were acquired near or post peak SWE, with the exception of 2017 when the first mid-winter acquisition occurred at the end of January. The validation data are three upper elevation in situ snow depth sensors from the California Cooperative Snow Survey network within the Yosemite National Park, and were used to validate the 51 ALS over time. ALS grids cells were averaged in a $9-\mathrm{m}^{2}$ area overlapping the snow depth sensor location for comparison. 

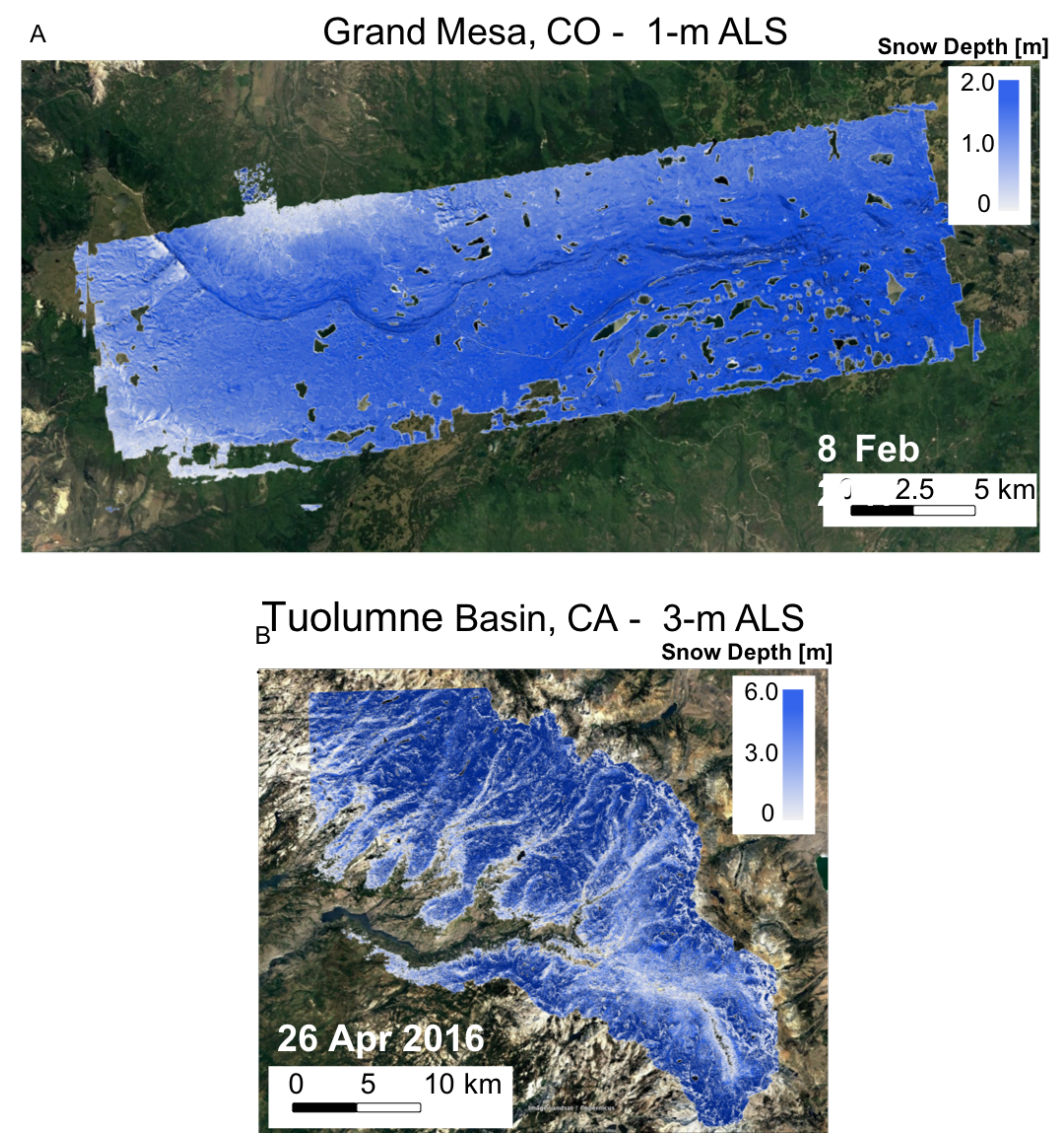

Figure 1.2: Single ALS at each site. (A) Grand Mesa, CO on 8 February 2017 and (B) Tuolumne Basin, CA on 26 April, 2016.

\subsubsection{Hydrologic Application of Basin Scale Studies}

Lidar technology has come a long way, partially due to the influx of several Earth system disciplines benefiting from its sub-decimeter vertical uncertainty (Deems et al., 2013). The high accuracy comes from coupling airborne laser platforms with highprecision GPS and inertial measurement unit (IMU) systems. This combination of sensors provides the necessary accuracy from repeat flights over a basin to allow snow depth retrieval. Typical in situ sensor networks are either sparsely distributed throughout a large basin, often limited to middle and lower elevations where terrain is 
flatter and more accessible, or densely concentrated in a small headwater catchment zone. Across larger mountain river basins, these networks typically do not adequately capture the steep gradients in temperature, precipitation, and rain versus snow fraction (Zhang et al., 2017). Water managers, responsible for regulating downstream flow, are in need of mountain water balance information to accurately assess snow storage volumes. Thus, sensor networks alone lack the spatial coverage needed to make representative basin-wide decisions (Hedrick et al., 2018).

\subsubsection{Errors and Uncertainties of Lidar Data Collection}

Lidar has been used to map snow depth for two decades now. Studies that have coincident snow depth data have reported vertical accuracies ranging from $8-30 \mathrm{~cm}$, and listed the known uncertainties associated with using lidar-derived snow depth products (e.g. Reutebuch et al., 2003; Hopkinson et al., 2004; Trujillo et al., 2007; Deems et al., 2006, 2013; Mazzotti et al., 2019; Currier et al., 2019). Accuracies range in magnitude due to 1) size and terrain type of validation datasets, and 2) induced error from the IMU system that tracks the motion associated with the aircraft movements (Deems et al., 2013). Measurement uncertainty has the potential to increase both horizontally and vertically in complex steep topography or when aircraft altitude varies (Deems et al., 2013). Whereas, ALS performed over flat surfaces and when the aircraft maintains a fixed height are prone to less uncertainty. Moreover, the flight parameters vary by study, terrain complexity, and instrument vendor, causing variation in reported error quantities. Vendors must consider what data standard they would like to achieve when determining point density (number of points per square 
meter). For example, we know that lower density point-clouds over dense conifer canopy cover results in a smaller chance of obtaining ground reflections (Hopkinson et al., 2012).

Ultimately, errors and uncertainty should be considered for each ALS, since so much of it depends on the aircraft flying parameters such as the laser scan frequency, aircraft height, and atmospheric cloud conditions. The specific instruments aboard the aircraft (i.e. laser, GPS, and IMU) also determine the overall measurement uncertainty. Lastly, the site's topographic complexity and vegetation density, and chosen post-processing approaches, play a roll in the accuracy of the final product. One approach to gain accuracy and reduce overall long-term costs, would be to obtain a higher density point-cloud for the snow-free period, and reduce the point density on subsequent snow-on periods. This would approach would result in a more accurate baseline snow-free digital elevation model (DEM) which is used every time to make a snow depth map.

\section{Data Post-Processing}

Post-processing of lidar acquisitions can occur a few different ways. Data can be processed via proprietary methods from the vendor and made available as an end user product; all ALS used in this manuscript were processed using ASO procedures (Painter et al., 2016), which have evolved over the six-year collection period. As an end user, the post processing sources of error are unknown since algorithms are proprietary. Alternatively, there are software programs available (e.g. lastools, http://rapidlasso.com/lastools/)) that can process point-cloud data. For this option refer to the Currier et al. (2019) for a streamlined workflow; note that the ALS error 
reported in Currier et al. (2019) of $8 \mathrm{~cm}$ is not for the ASO-provided depth product, but rather the custom processed point cloud.

\subsubsection{Data Preparation}

\section{Grand Mesa - Overlapping ALS points with snow-probe transects}

ALS validation points were selected where grid cells overlapped with snow-probe transect points. The optimal ALS window size to average snow depths was found which minimized the root-mean-square-difference (RMSD) and maximized the correlation coefficient $(R)$ (Figure 1.3). On average, a 4-m radius window was found to be optimal, in good agreement with the expected positioning error of the ground observations. Thus, ALS validation points were computed from an average overlapping window size of $64-\mathrm{m}^{2}$ (i.e. 64 grid cells at 1-m resolution per snow depth probe). 

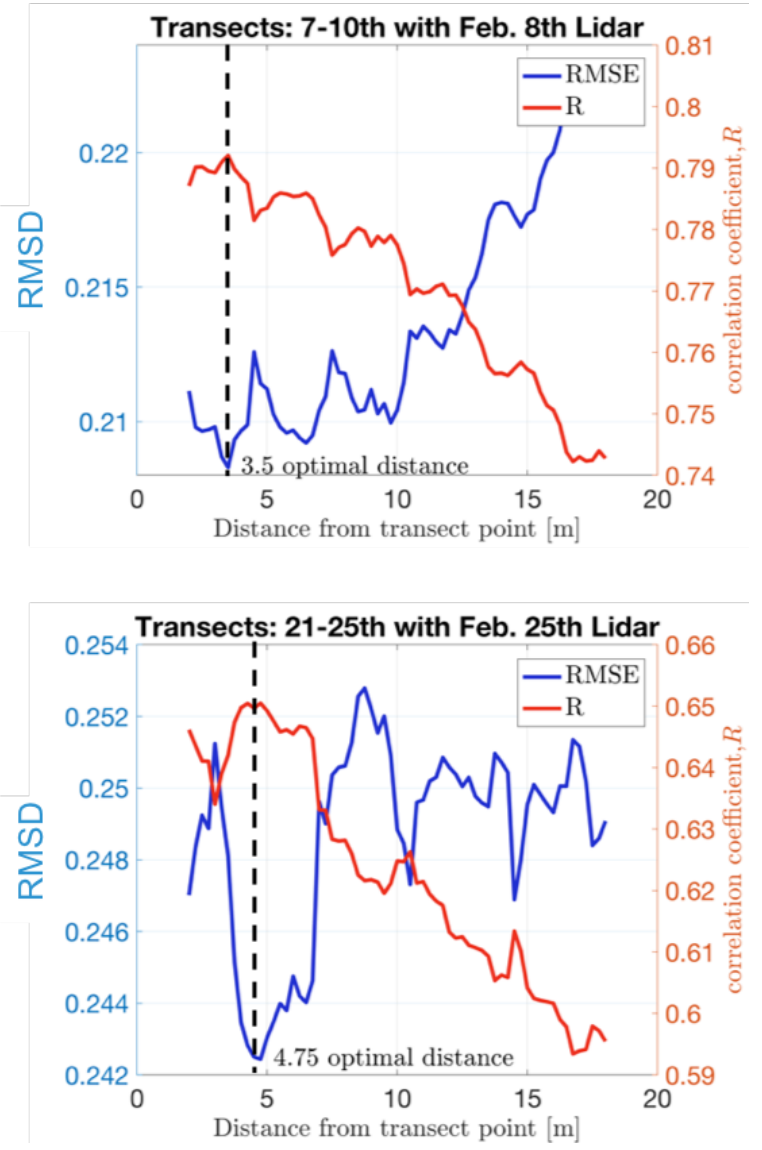

Figure 1.3: Lidar window size optimization. Lowest RMSD (y-axis, left) and highest correlation coefficient (y-axis, right) were determined to opti-mize overlapping lidar selection to snow-probe transect point.

\section{Tuolumne Basin - Snow depth sensors}

Snow depths from three meteorological (met) stations were obtained from Dana Meadows (301507E, 4196686N, 2988 m, DAN), Tuolumne Meadows (301526E, 4196696N, 2622 m, TUM), and Slide Canyon (286737E, 4218733N, 2797 m, SLI), which are managed by the California Department of Water Resources. Data were obtained through the California Data Exchange Center portal (https://cdec.water.ca.gov/). Data were checked for continuity and gaps were filled with a rolling mean linear interpolation. 


\section{Xarray Framework to Ingest Dataset}

Some details regarding the framework used to ingest ALS data are outlined, as this became a computational challenge due to the size of the dataset; the dataset as a whole was >80 GB, and each ALS had close to 3 million points after re-gridding to 20-m. From Python's open source package library, we utilized Xarray, a multidimensional, metadata-storing tool, compatible with dask computing (Hoyer \& Hamman, 2017). Dask automates parallel computing to avoid bottle-necking and memory error crashes. With Xarray you can apply operations over different dimensions (i.e. space and time), select labeled values instead of relying on multiple integer indicies, and perform vectorized mathematical operations across multiple dimensions. The dask capability made multi-dimensional computation possible on a typical desktop computer by initializing fixed chunk sizes to avoid computational memory errors. ALS rasters were loaded along with a basin mask, digital elevation model (DEM), and vegetation height layer. These were all aligned in space (x, y) and stacked vertically to create a data package cube that was stored as a netCDF file.

\subsection{Results}

\section{Grand Mesa}

In general, the ALS and snow-probe transects had similar distribution shapes, but the snow-probe transects consistently had higher snow depths when compared to the lidar for both 8 and 25 February (Figure 1.4). On average, the median difference, or bias was $7 \mathrm{~cm}$, between snow-probe transects and ALS. The root-mean-square-difference (RMSD) for the two ALS dates are 20 and $24 \mathrm{~cm}$, and the correlation coefficient 
$(\mathrm{R})$ is 0.78 and 0.64 , respectively (Figure 1.5, Table 1.1). Validation points were classified as either in the open or in the forest, and both measurement approaches show snow depths were consistently deeper in the open compared to in the forest (Figure 1.5). Interestingly, the difference between snow-probe transects and ALS shows no statistical difference between open and forested areas; this was a bit unexpected as it was thought that lidar depths would be less accurate in the forest. This may be due to the very high point density used during SnowEx (Figure 1.5).

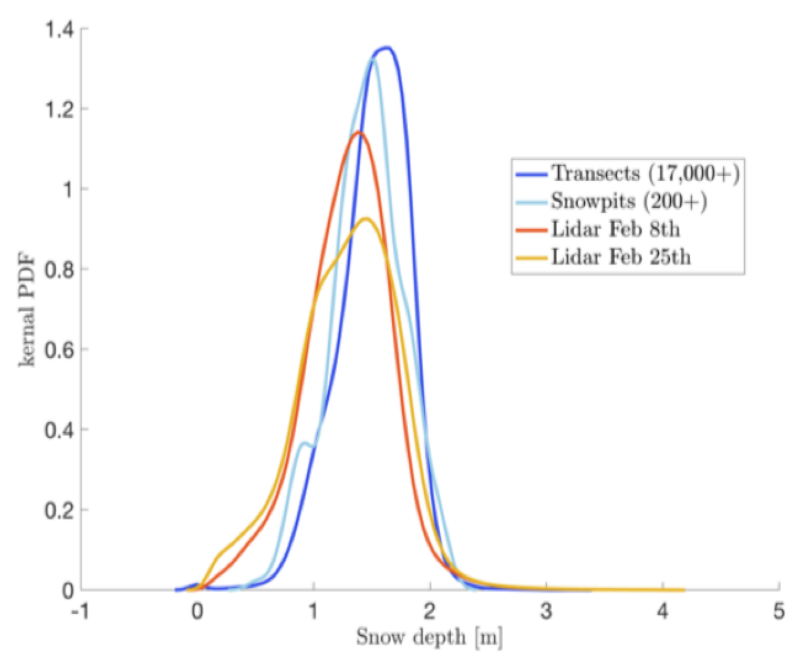

Figure 1.4: Kernel probability density function (PDF) for ground-based and airborne lidar survey observations. 

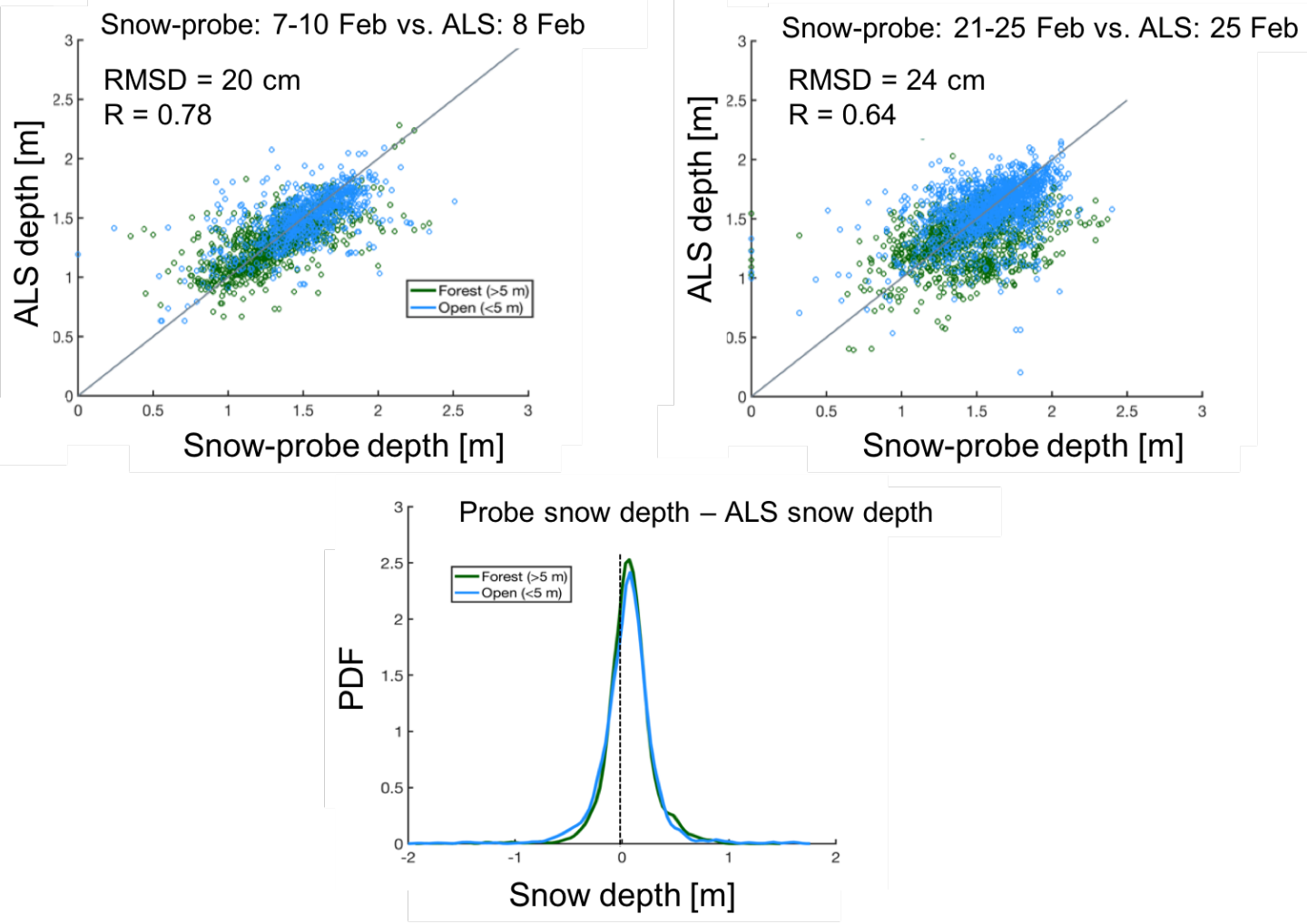

Figure 1.5: Comparison of ALS with ground-based snow-probe transect observations. Points are categorized by forest $(\geq 5 \mathrm{~m})$ and open $(<5 \mathrm{~m})$. (top left) ALS date is $8 \mathrm{Feb}$, snow-probe 7-10 Feb. (top right) ALS date is $25 \mathrm{Feb}$, snow-probe 21-25. (bottom) Difference between snow-probe measurement and overlapping ALS measurement.

Table 1.1: Summary results for ALS and snow-probe transects. $\mathrm{RMSD}=$ root mean square difference, $R=$ correlation coefficient

\begin{tabular}{llll}
\hline \multicolumn{1}{c}{ Probe } & \multicolumn{1}{c}{ ALS } & RMSD & $R$ \\
snow depths & snow depths & $(\mathrm{cm})$ & \\
\hline Feb 7-10 & Feb 8 & 20 & 0.78 \\
Feb 21-25 & Feb 25 & 24 & 0.64 \\
\hline
\end{tabular}




\section{Tuolumne Basin}

Three meteorological stations within the upper elevations of Tuolumne Basin show reasonable temporal agreement with associated ALS grid cells (Figure 1.6). In general, the depth sensors at all three sites had higher snow depths compared to the ALS. Periods of no snow align best, while periods after peak snow depth tend to deviate in extreme years (2015 and 2017). In 2014 there were several times where the ALS had zero snow cover while the Dana Meadows depth sensor recorded between 10-100 cm, and in one case $250+\mathrm{cm}$. The RMSD at Dana Meadows is $58 \mathrm{~cm}$, Tuolumne Meadows is $22 \mathrm{~cm}$, and Slide Canyon is $38 \mathrm{~cm}$ with associated high correlation coefficients $(R)$ of $0.89,0.96,0.97$, respectively. 

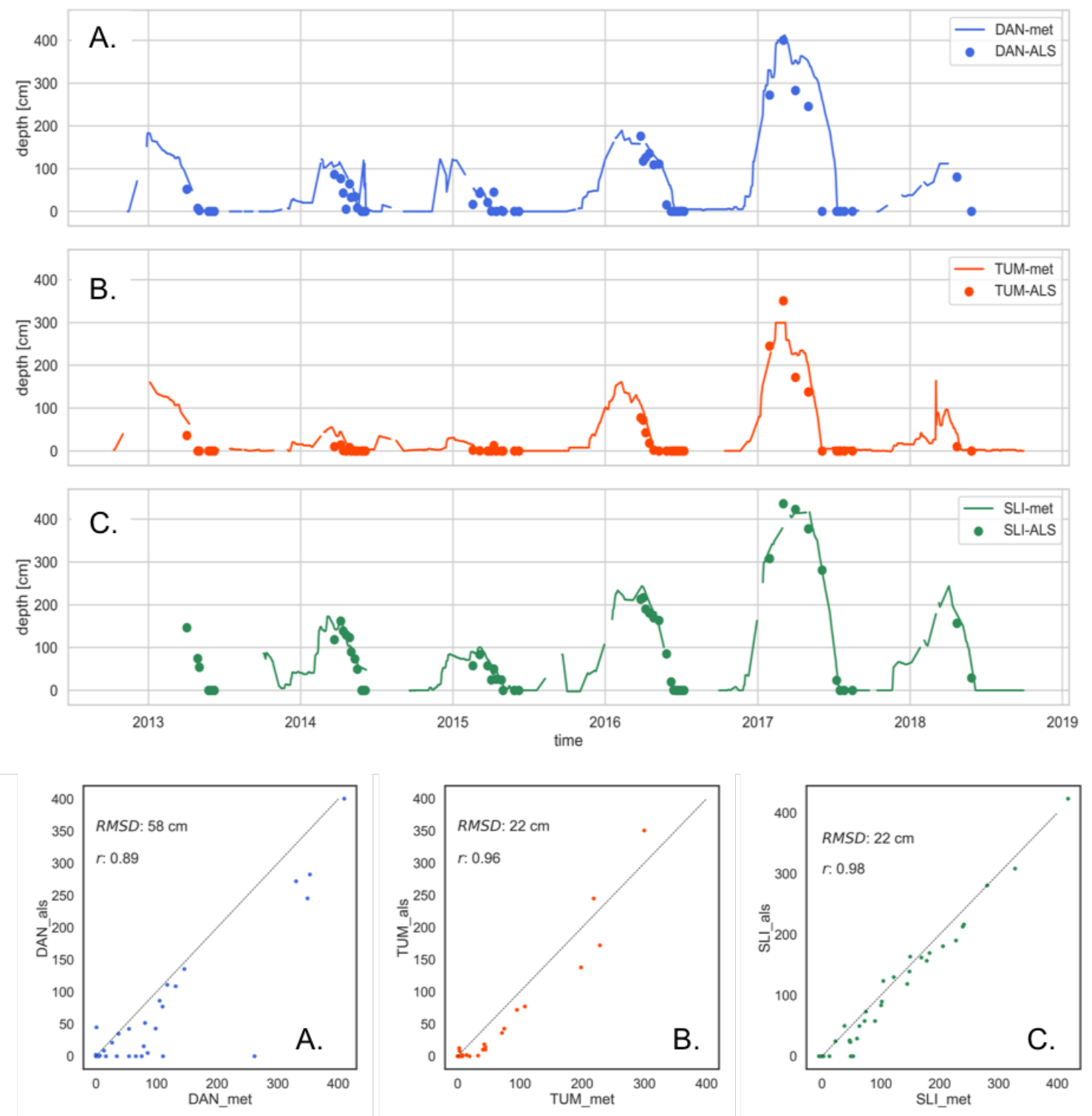

Figure 1.6: ALS temporal validation with three metrological sites (A) Dana Meadows (blue), (B) Tuolumne Meadows (red), (C) Slide Canyon (green). 


\subsection{Discussion}

\section{Grand Mesa}

Currier et al. (2019) did an extensive evaluation of the three different snow depth measurements types (ALS, TLS, snow-probe transects) from the 2017 SnowEx campaign. Our median difference between snow-probe transects and ALS agrees well, in that snow-probe transects consistently have a higher snow depth of $7 \mathrm{~cm}$ (this study) and $6 \mathrm{~cm}$ (Currier et al., 2019). Conversely, the RMSD for the two measurement types is different for the overlapping ALS flight date, 8 February. This study found $20 \mathrm{~cm}$ RMSD while Currier et al. (2019) found $8 \mathrm{~cm}$ RMSD. Although both studies used the same ALS date, other differences between the comparison likely explain the large RMSD. First, this study uses the ALS product, while Currier et al. (2019) used the snow-free and snow-on point-cloud to generate a snow depth map where there was more control over ground point selection methods. Second, this study computed RMSD for a 4-day period, 7-10 February (i.e. week 1 field campaign), whereas Currier et al. (2019) selected snow-probe transects from a 2-day period, 8-9 February (tighter temporal alignment to the 8 February flight). Meteorological data from two nearby sites show that 9 and 10 February did experience days with $>0{ }^{\circ} \mathrm{C}$ and snow depth did decrease for those two days by approximately $5 \mathrm{~cm}$.

The general snow depth trend at Grand Mesa is an overall west-east gradient, where the west end has shallower snow depths compared to the east end where snow is deeper (Figure 2.2). This makes the results from Figure 1.5 interesting because overall the open snow-probed areas had deeper snow, yet the west end is generally more dominated by open terrain where snow was shallower. Similarly, vegetation increases to the east where depths also increase, yet the total forested snow-probe 
measurements have shallower snow.

ALS at 1-m with a high-resolution point cloud is not always available when selecting different areas of ALS coverage. Moreover, the famously flat, continuous terrain with large vegetation-free areas that Grand Mesa provides catered well to lidar-derived snow depth mapping. Additional validation should be considered for regions with steep terrain as larger uncertainties are expected.

\section{Tuolumne Basin}

The ALS temporal validation in Tuolumne Basin gives context to the ALS time series dataset. However, we note that the met site network is not representative of the basin as a whole, since they are located in flat, vegetation-free clearings, and never above treeline. We expect some amount of error with the collection of ALS, but for the purposes of the following chapters, we are focused on snow depth distribution patterns, which are extremely well captured by the 3-m ALS products instead of constraining the dataset's uncertainty for a hydrologic streamflow model application.

\subsection{Conclusion}

Airborne lidar technology has proven useful for studying snow depth distribution and is capable of capturing the spatial distribution of snow at an unmatched resolution. Validation studies, both ours and more thorough analyses, have constrained the expected differences between different snow depth measurement techniques. On 8 and 25 February the RMSD between snow-probe transects (4-day period) and ALS are 20 and $24 \mathrm{~cm}$, respectively. While our RMSDs are larger than Currier et al. (2019) the longer snow-probe transect window (4 versus 2 days) and the difference in using the ALS product versus the point-cloud likely explain the differences. 
There is no other dataset where 51 ALS over a six-year period can be compared to in situ snow depth observations. This is a powerful validation tool when you have confidence in the snow depth sensor network (extreme years, limited personnel, and remote depth sensor locations make it hard to maintain high elevation temporal datasets). High resolution temporal datasets, such as depth sensors give context and will continue to be used in the foreseeable future as remote sensing efforts advance.

The disadvantages of ALS datasets are that data collection is very costly and weather dependent, temporally limited, and somewhat restricted on regional coverage. Until other remote sensing products meet the performance of ALS, lidar will continue to serve as an invaluable tool to map snow depths and use as assimilation data in high resolution models. By this reasoning, we should continue to leverage the spatial information gleaned from ALS datasets to further our understanding of snow distribution patterns and the temporal scales over which they are consistent. 


\section{CHAPTER 2:}

\section{WHOLE BASIN TRENDS IN A MULTI-YEAR HIGH RESOLUTION AIRBORNE LIDAR SNOW DEPTH DATASET}

\section{$2.1 \quad$ Introduction}

Snow is a climate-dependent, terrestrial water resource that plays a dominant role in the seasonality of fresh water availability. One-sixth of the world's population resides in snowmelt-dependent and low-reservoir-storage regions (Barnett et al., 2005). Snow is particularly important in the western United States, specifically in the state of California, where groundwater storage is depleting at increasing rates (Famiglietti et al., 2011) and climate change has increased the year-to-year variability in total snowfall (Bair et al., 2018). Monitoring the seasonal snowpack progression is challenging due to the large spatiotemporal variability of snow properties (Blöschl, 1999).

Water managers continue to rely on sparse networks of meteorological sites to guide reservoir storage decisions for flood control, power generation, and water allocation to meet domestic, agricultural, and ecosystem needs. Despite the challenges in quantifying snow water equivalent (SWE), the recent availability of finer spatial resolution remote sensing capabilities and data assimilation into models has benefited 
water supply forecasting in the Sierra Nevada (Painter et al., 2016; Hedrick et al., 2018). Airborne lidar surveys (ALS) offer an unparalleled method for measuring snow depth variability, as it is the primary remote sensing technique used for snow depth at both the large and small basin scales (Deems et al., 2006; Trujillo et al., 2007, 2009; Cline et al., 2009; Elder et al., 2009; Kirchner et al., 2014; Painter et al., 2016; Hedrick et al., 2018; Henn et al., 2018). While ALS can be costly and weather dependent, California intends to integrate regular ALS to capture the annual snow depth evolution over the next ten years, by increasing the water supply forecasting budget. As ALS become regular over greater portions of the Sierra Nevada, it is important for us to understand the stability of inter- and intra-annual snow distribution patterns, so that we can provide guidance on the timing and required number of surveys.

A remote sensing time series dataset enables studying snow depth distribution patterns for the timing, consistency, and repeatability of spatial accumulation and melt patterns. Previous work (e.g. Erickson et al., 2005; Deems et al., 2008; Sturm \& Wagner, 2010; Schirmer et al., 2011; Schirmer \& Lehning, 2011; Winstral \& Marks, 2014) demonstrates that physical parameters force consistent and repeated patterns in snow accumulation (i.e. snow drift and scour zones). Studies using in situ ground observations (Winstral et al., 2014; Winstral \& Marks, 2014), sparse networks of meteorological stations (Susong et al., 1999; Garen \& Marks, 2005), and temporally limited remote sensing products (Deems et al., 2008; Trujillo et al., 2009) have all focused on correlating a suite of physical parameters to the observed snow patterns. Physical parameters such as precipitation, elevation, wind, topography, and vegetation that affect snow depth distribution are challenging to model over large regions. The ALS time series dataset in Tuolumne Basin offers the most complete spatio- 
temporal snow depth dataset to study snow depth distribution patterns at the basin scale.

The objective of this research is to determine whether there is snow depth correlation between years, and if so, identify spatial snow distribution patterns using the high-resolution (3-m) ALS dataset. Identifying snow distribution patterns and quantifying pattern consistency (and variability) over time will benefit high-resolution water supply forecasting by more accurately distributing snow in space and forecasting melt timing. These results also provide a tool for optimum placement of new long-term monitoring sites, and design of manual snow surveys. Although snow distribution patterns will vary for neighboring or distant basins, the results found will inform future ALS acquisition planning.

\section{$2.2 \quad$ Study Area}

The Tuolumne Basin is part of the Sierra Nevada mountain range in eastern California (Figure 2.1). The Tuolumne River and its tributaries comprise a widely studied basin that is the main source of water for over two million people in the San Francisco Bay Area and is largely protected and managed by Yosemite National Park. Snowmelt is temporally stored in the Hetch Hetchy Reservoir at the basin outlet, before it is released to downstream users. The basin's total area is $1180 \mathrm{~km}^{2}$ with a large portion (90\%) of that area over $2000 \mathrm{~m}$ in elevation, which is larger and higher than most research basins in the western US (Lundquist et al., 2016; Hedrick et al., 2018). The basin is a snow-dominated system where $80-90 \%$ of the precipitation input from the mid to high elevations (2100-4000 m) occurs during the winter months and is stored as snow until the melt season when streamflow peaks (Rice et al., 2011). The lowest

elevation in the basin is at $1150 \mathrm{~m}$, just above California's Central Valley floor, and 
extends to the crest of the Sierra at $4000 \mathrm{~m}$. The tree line is near $2900 \mathrm{~m}$ and the predominant forest cover is firs and pines (Hedrick et al., 2018; Ferraz et al., 2018). Beneath the shallow alpine soils is primarily granodiorite bedrock. This highly intact bedrock stabilizes channel formation and simplifies modeling efforts, as melt losses to groundwater are estimated to be very small (Lundquist et al., 2016). The upper end of the Dana Fork, one of two main forks that make up the Tuolumne River, is underlain by metavolcanic and metasedimentary rock, which are more susceptible to melt losses into the groundwater (Lundquist et al., 2016).

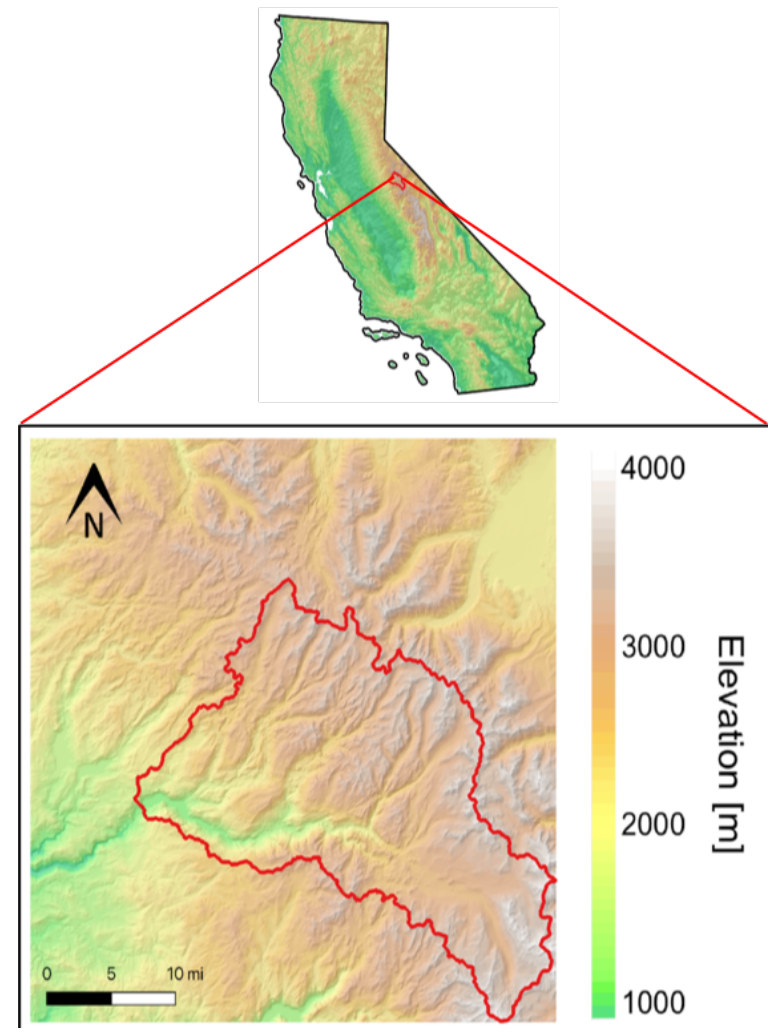

Figure 2.1: Digital elevation model (DEM) for the Tuolumne Basin study site. The Tuolumne Basin is located in the Sierra Nevada Mountain Range in eastern California. 


\subsection{Background and Methodology}

\subsubsection{Airborne Lidar Survey (ALS) Dataset}

The six-year (2013-2018) dataset of 51 ALS snow depth maps for the Tuolumne Basin were collected by the Airborne Snow Observatory (ASO) at 3-m resolution (Table 2.1) (Painter, 2018b). In the first three years of data collection, the Sierra Nevada experienced lower than average years, with 2015 being an extreme drought year. 2016 and 2018 were representative of an average snow year, and 2017 was a historically well-above average snow year. Refer to Figure 2.3a for the annual magnitude of snow depth and temporal coverage captured by the ASO's dataset. This study re-gridded the 3-m ASO product to 20 -m by resampling with bilinear interpolation (Figure 2.4). At 20-m resolution, each ALS has 2.67 million grid cells above $2000 \mathrm{~m}$ in elevation (see section 3.3) within the basin domain.

Table 2.1: Count and temporal span of ALSO dataset

\begin{tabular}{ccc}
\hline Year & $\begin{array}{c}\text { Number } \\
\text { of ALS }\end{array}$ & $\begin{array}{c}\text { First-Last in } \\
\text { Time Series }\end{array}$ \\
\hline 2013 & 6 & 3 Apr - 8 Jun \\
2014 & 11 & $23 \mathrm{Mar}-5$-Jun \\
2015 & 10 & 18 Feb - 8 Jun \\
2016 & 13 & $26 \mathrm{Mar}-8 \mathrm{Jul}$ \\
2017 & 9 & $29 \mathrm{Jan}-16 \mathrm{Aug}$ \\
2018 & 2 & $23 \mathrm{Apr}-28 \mathrm{May}$ \\
Total & $\mathbf{5 1}$ & \\
\hline
\end{tabular}




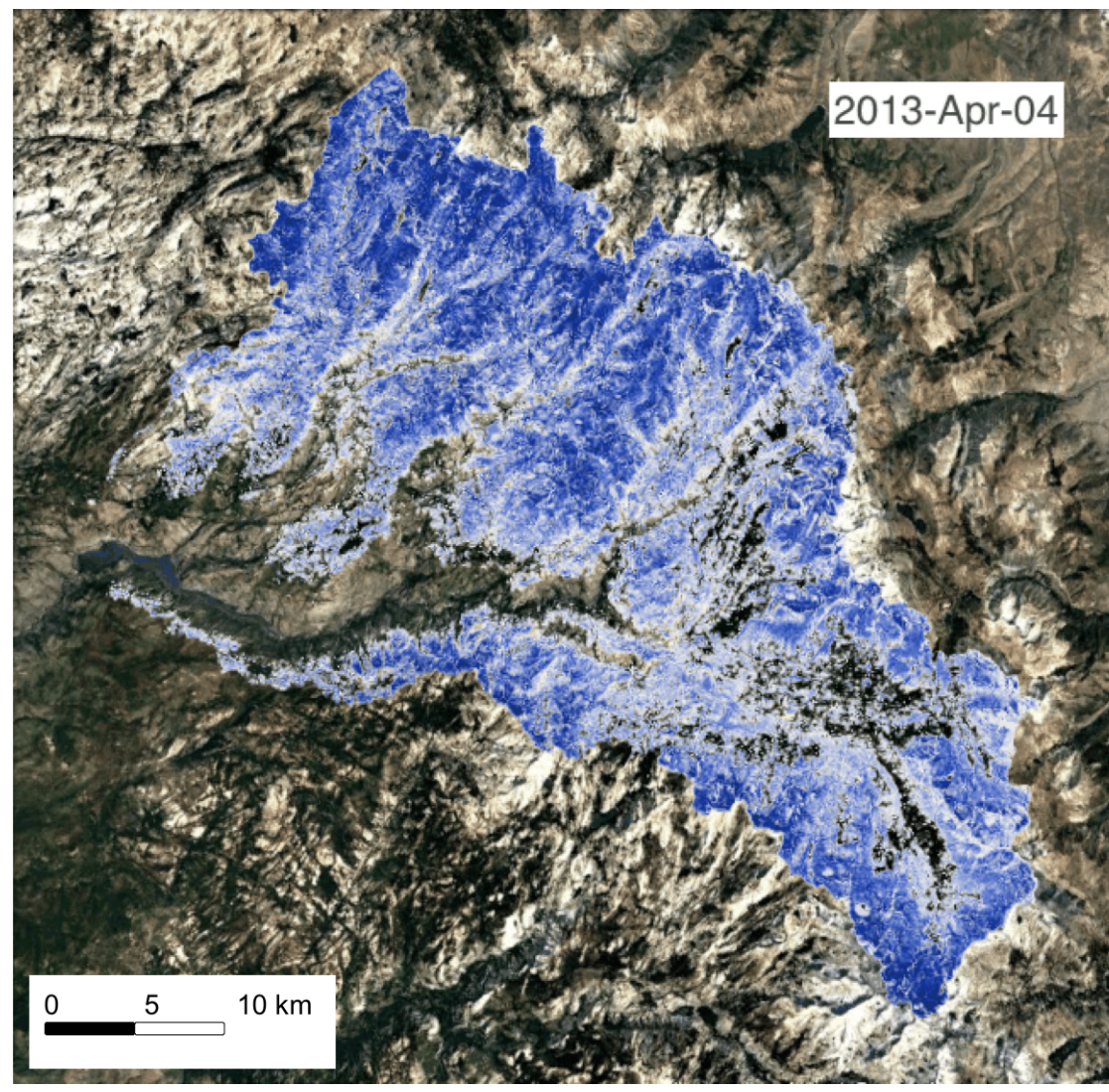

Snow Depth [m]

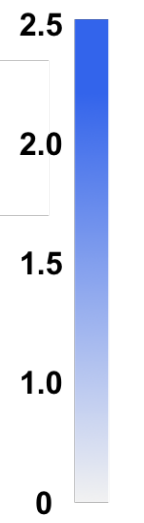

Figure 2.2: Spatial coverage from one of 51 ALS snow depth maps of Tuolumne Basin, in the Sierra Nevada mountain range in Eastern, California. 


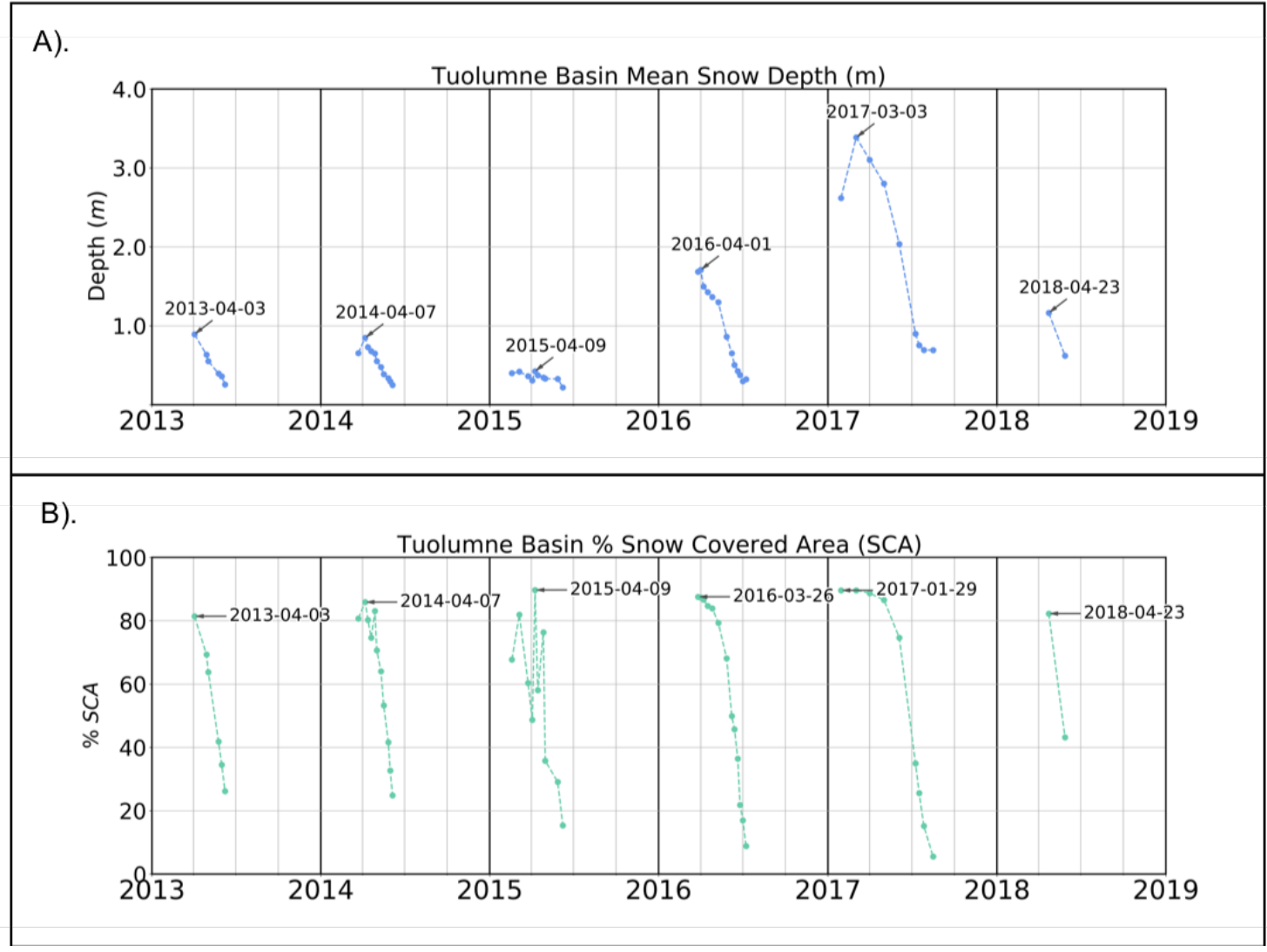

Figure 2.3: (A) Mean snow depth values for the whole basin. Each ALS occurrence is marked (blue points) and connected (dashed blue line) by season. Labeled dates mark the maximum basin-wide mean snow depth. (B) Percent snow covered area (SCA).

\subsubsection{Inter-Annual Correlation}

As an initial step, we investigated the correlation between snow years. One ALS was selected from each year nearest the basin's peak SWE, as modeled by the USDA Agricultural Research Service-Northwest Watershed Research Center (USDA ARSNWRC) at 50-m resolution (Marks et al., 1999; Hedrick et al., 2018). Snow depths were standardized by computing standardized depth values (SDV), also commonly 
referred to as a Z-score, according to methods used by Sturm \& Wagner (2010).

$$
S D V_{i}=\left(d_{i}-\mu\right) / \sigma
$$

Each ALS product is standardized according to the mean basin snow depth $(\mu)$ and standard deviation $(\sigma)$ for snow covered areas for an individual ALS. The SDV have a distribution where $\mu=0$ and $\sigma=1$ for each ALS. For the inter-annual comparison between two years, only grid cells that had snow depths greater than zero for each year were compared.

\subsubsection{Empirical Cumulative Distribution Function (ECDF)}

In general, snow depth distributions are not normally distributed. This is because snow depths are never negative and there is a large concentration of depths that are at or near zero. Snow depth then increases during the accumulation period, and steadily decreases during the ablation period, followed by a gradually diminishing tail of deeper snow depths on the right-hand side of the distribution (Figure 2.4). Because of the distribution shape, it was necessary to choose a non-parametric method to investigate snow depth distribution trends over time and space. The empirical cumulative distribution function (ECDF) is a non-parametric estimator of the underlying cumulative distribution function of a random variable. This approach provides quantiles of the ranked snow depth distribution. The equation to compute an ECDF is:

$$
F_{n}(x)=1 / n \sum_{i=1}^{n} I\left(x_{i} \leq x\right)
$$




$$
I\left(x_{i} \leq x\right)= \begin{cases}1, \text { when } & x_{i} \leq x \\ 0, \text { when } & x_{i}>x\end{cases}
$$

Where $x$ is the ordered number of observation points from smallest to largest, $x_{i}$ is the snow depth at a given grid cell, and $n$ is the total number of observations. $I$ is the indicator function that gets summed, and $F_{n}(x)$ is an estimate of the cumulative distribution function. The result is a step function; however, in our case due to the large number of data points $(n=2.67$ million per ALS) the ECDF resembles the smooth underlying CDF, but the benefit is the quantiles are sampled directly from the dataset. 

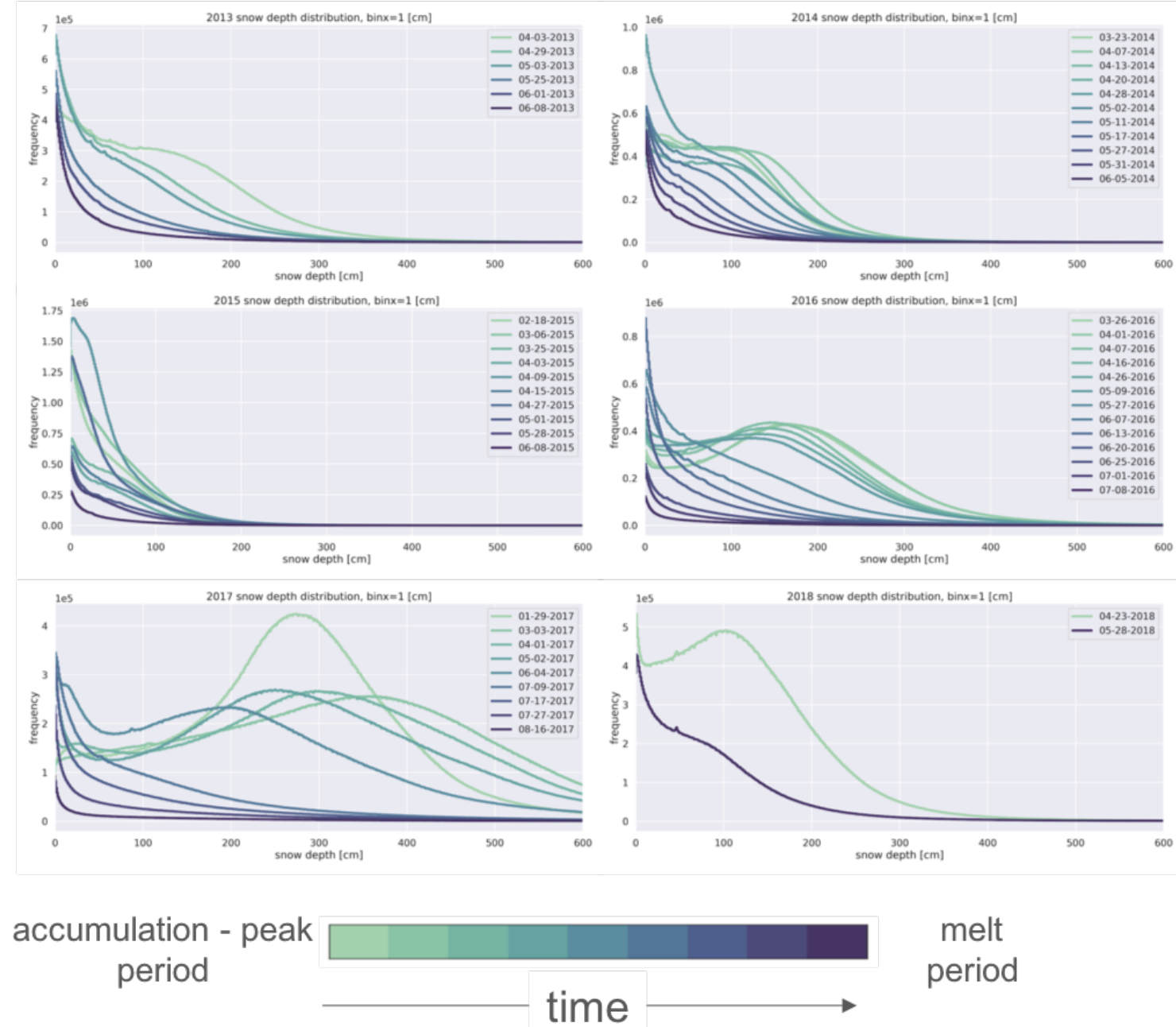

Figure 2.4: Snow depth distribution plotted by year for all ALS in the Tuolumne Basin. Color scheme shows first to last ALS by time. For most years the first flight was near peak SWE timing in the basin. Snow depth distribution is not normally distributed

Ultimately, the rankings assigned by the ECDF are used to compare snow distribution patterns between years. The ECDF provides the percent of the basin at a given snow depth or below. For example, at the $50^{\text {th }}$ percentile the corresponding snow depth represents the basin median. The value of the ECDF for the depth at 
each pixel is found and plotted spatially. To investigate the depth patterns (consistently deep, average, or shallow) and pattern consistency (greater or less variability) the mean and range of the ECDFs across the ALS, respectively, were computed.

\subsubsection{ALS Selection for ECDF Analysis Similar Snow Cover Extent - inter and intra-annual comparison}

It is not reasonable to study all 51 ALS using the ECDF method, as it would be challenging to interpret a large spread in the range of all ECDFs without conflating the timing of distinct accumulation, peak, and ablation periods. Therefore, we set a criterion to select ALS with $80 \%$ or greater snow covered areas (SCA). 21 ALS met this threshold, which in most cases constrained ALS to periods between March - May, with the exception of earlier ALS in 2015 when snow peaked unusually early, and later flights in 2017 when snow remained deep and, in the basin, well into June (Figure 2.3b). Although the selected ALS occur during both the accumulation and melt periods, the $80 \%$ SCA threshold assumes that the basin did not experience intense melting. To avoid interpreting areas more frequently subjected to early melt or mid-winter rain we selected snow depths at $2000 \mathrm{~m}(\sim 6500 \mathrm{ft}$.) and above (Roche et al., 2018). This still offers a large basin-wide elevation gradient of 2000-4000 m.

\section{Peak SWE timing - inter-annual comparison}

The same 6 ALS that were used for the inter-annual correlation analysis were used for the inter-annual ECDF comparison. Although the timing of the ALS acquisition does not perfectly align with the modeled peak SWE timing, there is far less seasonal variation for this inter-annual selection. 


\subsubsection{Random Forest Classifier}

The outcome from the ECDF mean and range across surveys produce three categories for both depth patterns and pattern consistency. The categories for depth patterns are deep, average, and shallow snow depths, and the categories for pattern consistency are greater, average, or less variability in spatial snow distribution. To predict these categories across different terrain parameters (elevation, aspect, and slope) we consider a supervised learning algorithm. We use a random forest to construct a set of classifiers which is composed of a combination of multiple decision trees. A decision tree is a model that relies on partitioning the feature across different labels. In this case, the topographic parameters are the features and the predictor algorithm partitions the feature information and eventually classifies the ECDF values into one of the three categories mentioned above for both the mean and range inputs.

The random forest classifier is trained on $30 \%$ of the data and tested on the remaining $70 \%$. There are 100 combinations of decision trees to alleviate the sensitivity of having only a single decision tree to handle changes to data inputs. Thus, the random forest result comes from a combination of decision trees. To avoid overfitting, a cutoff point, or pruning depth, was set to 20. The pruning depth maximizes the depth the tree can grow before the final classification node is reached. If run without the pruning threshold the trees averaged 78 for a maximum depth. The result of the random forest classifier provides the feature importance for the selected terrain parameters that influence snow distribution patterns and pattern consistency, providing insight into the relative influence of these three terrain parameters. 


\subsection{Results}

\subsubsection{Inter-Annual Correlation}

Standardized depth values (SDV) across the whole basin show strong correlation near peak SWE timing for year-to-year comparisons (Figure 2.5). The minimum correlation value $(r)$ is 0.67 and occurs during the two most dissimilar years, 2015 vs. 2017. The maximum $\mathrm{r}$ value is 0.89 and occurs during an average and high snow year, 2016 vs. 2017. Two other comparisons show similarly high correlation values for similar years; 2013 vs. 2014, both below average snow years and 2016 vs. 2018, both near average snow years. The median $r$ for all 15 one-to-one combinations is 0.79 , indicating that snow depth patterns are consistent in many locations across different winters. 


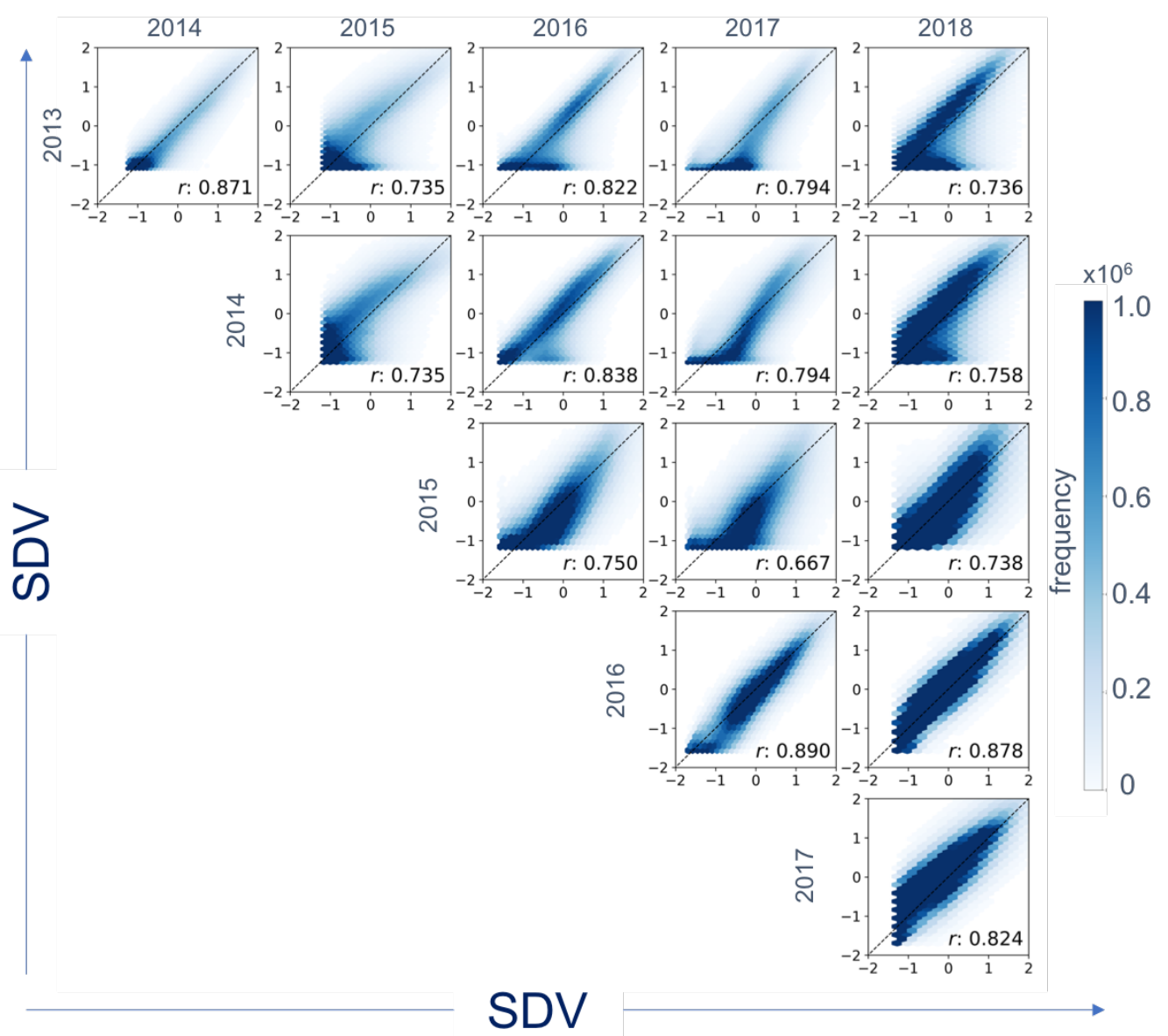

Figure 2.5: One-to-one correlation for each year with correlation value $(r)$. The two years with the greatest correlation are 2016 verse $2017(r=0.89)$, and the lowest correlation are 2015 verse $2017(r=0.66)$, the two most different snow years is recent history.

\subsubsection{Empirical Cumulative Distribution Function (ECDF) Mean of the ECDFs}

The interpretation of the mean ECDF values is that a value of 0.5 is the $50^{\text {th }}$ percentile, therefore it is at the median snow depth. Values below 0.5 represent areas below the median snow depth and are shallow. Values above 0.5 represent areas above the median snow depth and are deeper. Figure 2.6 shows a basin map for the mean 
of 21 ECDFs to identify where in the basin snow is ranked based on the quantiles that represent consistently deep, shallow, and median snowpack. The shallowest (red) snow in the basin is found at lower elevations, steep valley walls directly above the Hetch Hetchy Reservoir, and valley floors at higher elevations. Snow that averages in the $50^{\text {th }}$ percentile is found between deep and shallow zones and typically occurs where terrain is flat in the mid-elevations and on high peaks. The deepest (blue) snow in the basin is found almost exclusively at the highest elevations and concentrated just below prominent peaks. Figure 2.7 shows the basin map for the mean of 6 ECDFs nearest peak SWE. The snow depth patterns are nearly identical to Figure 2.6 . 


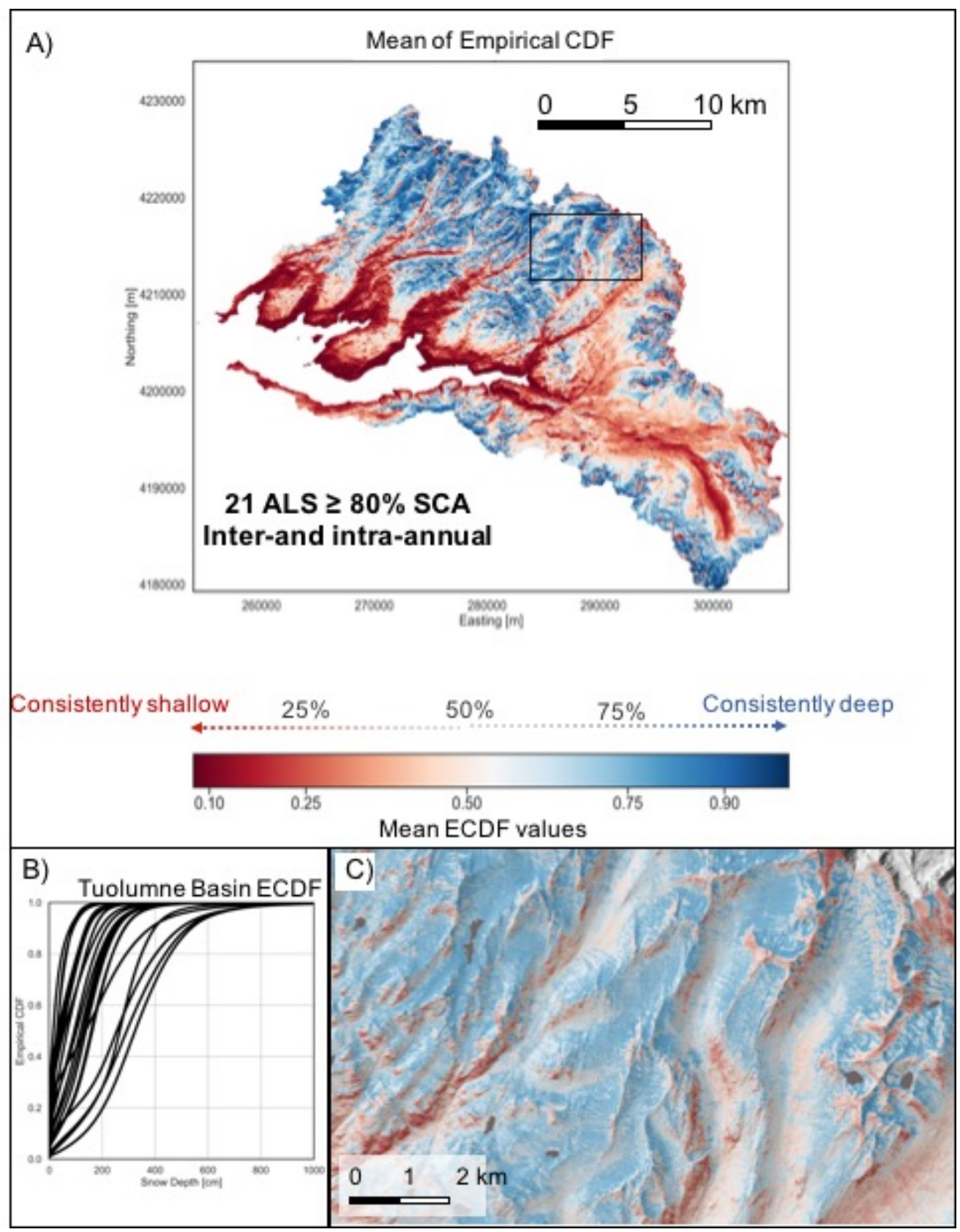

Figure 2.6: (A). Mean of the ECDF for 21 ALS with $80 \%$ and greater SCA. (B). 21 ECDFs of snow depth for the whole basin. (C) Close up of ECDF values from the mean ECDF (black extent box in A). Gray polygons are alpine lakes. 


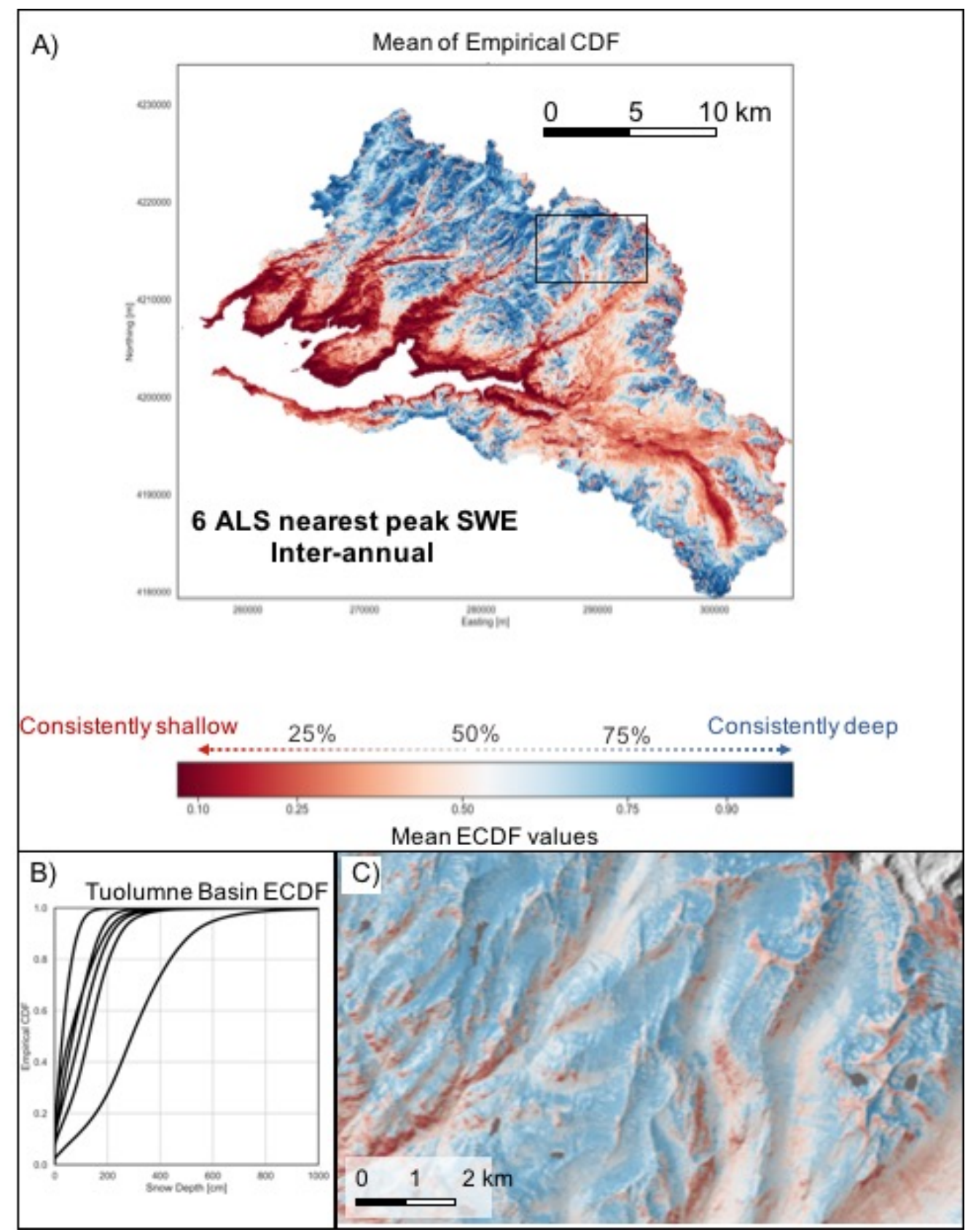

Figure 2.7: (A). Mean of the ECDF for 6 ALS nearest peak SWE. (B). 6 Empirical CDFs of snow depth for the whole basin. (C) Close up of ECDF values from the mean ECDF (black extent box in A). Gray polygons are alpine lakes. 


\section{Range of the ECDFs}

The range of the ECDFs describe how consistent the spatial patterns are by looking at the difference between the maximum and minimum ECDF value at the same location through time. A low range indicates there is little variability and the snow distribution at this location maintains a consistent patterns relative to the rest of the basin. Conversely, a high range value indicates the difference between the maximum and minimum ECDF was large, therefore snow distribution patterns are less consistent, and the location is more likely to experience shifts relative to the basin median. Figures 2.8 and 2.9 show the basin map for the range of 21 ECDFs with $80 \%$ SCA and 6 ECDFs nearest peak SWE, respectively. The difference between Figure 2.8 and 2.9 is that the range that covers inter- and intra-annual time periods (21 ALS $\geq 80 \% \mathrm{SCA}$ ) has greater variability (more blue) in snow distribution patterns at a given location than for the range of ECDFs nearest peak SWE timing (more yellow). 


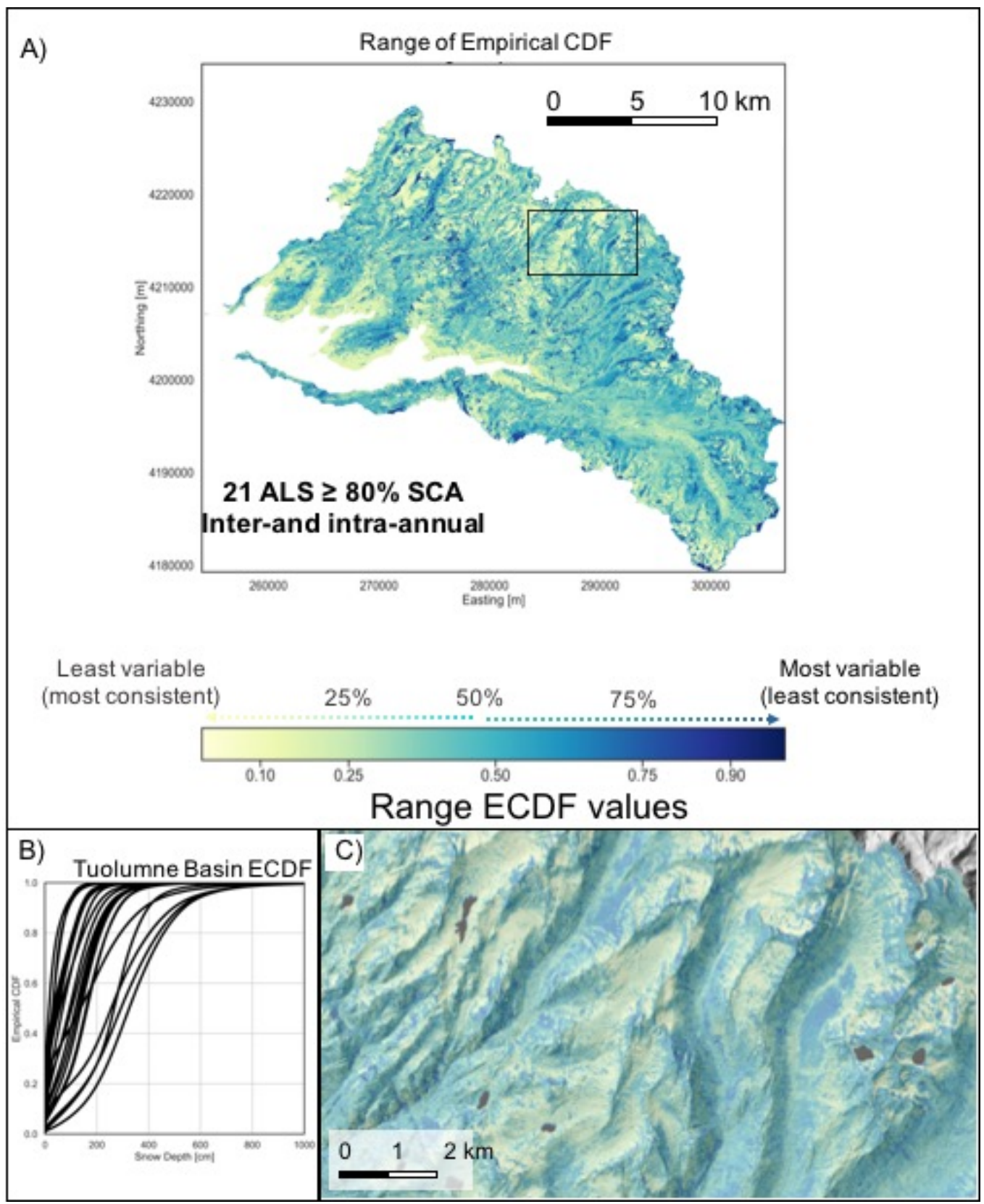

Figure 2.8: (A). Range (maximum - minimum) of the ECDF for 21 ALS with $80 \%$ and greater SCA. (B). 21 Empirical CDFs of snow depth for the whole basin. (C) Close up of ECDF values from the range of ECDF (black extent box in A). Gray polygons are alpine lakes. 


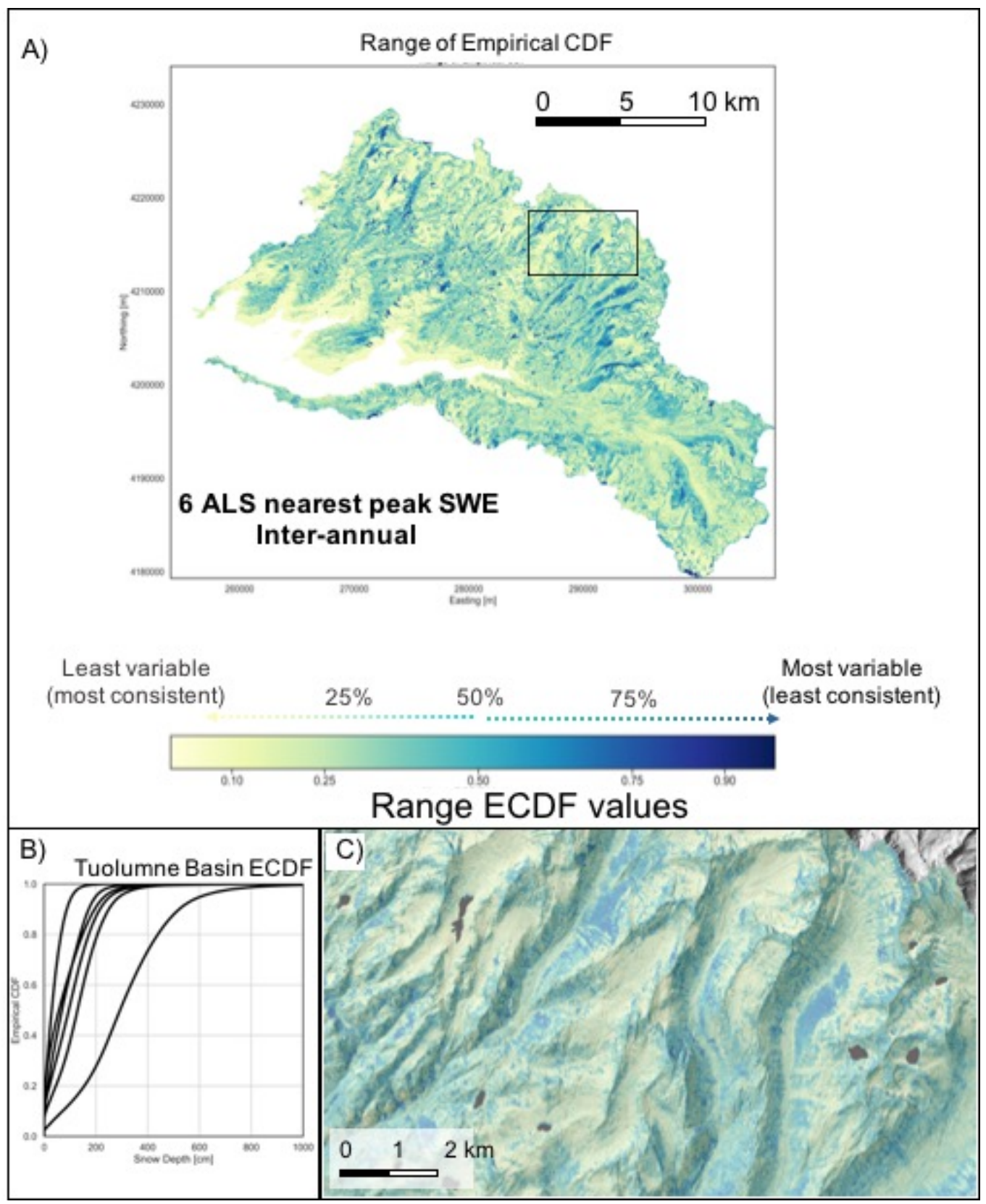

Figure 2.9: (A). Range (maximum - minimum) of the ECDF for 6 ALS nearest peak SWE. (B). 6 Empirical CDFs of snow depth for the whole basin. (C) Close up of ECDF values from the range of ECDF (black extent box in A). Gray polygons are alpine lakes.

For both figures 2.8 and 2.9 , the areas that similarly have greater pattern consis- 
tency (yellow) appear at the steep valley walls above Hetch Hetchy Reservoir, valley floors and high flat plateaus, and some upper elevation mountain slopes. Areas that experience a 50\% shift in quantile rankings (greenish) are predominantly at the midelevation hillslopes where vegetation is present and along long narrow ridgelines that divide parallel drainage valleys. Locations that range beyond the $50^{\text {th }}$ percentile (dark blue) are isolated to complex, mid-high elevation terrain that are both east and west facing hillslopes and concentrate just below ridgeline features. Basin edges and alpine lakes also show the highest variability in the range maps, but we suspect the data quality has been compromised on the edges, and water bodies were not consistently processed for the six-year period, and likely water levels varied year to year.

\section{Inter-Annual Comparison for Mean and Range ECDFs}

For comparison purposes, Figure 2.10 shows the inter-annual comparison for 6 ALS nearest peak SWE. The extents match the locations in Figure 2.8 and 2.9. The majority of the flat areas (valley floors or high elevation plateaus) that experience the most consistent snow distribution patterns (yellow) are dominated by consistently deep or shallow snow zones. Areas that experience the most variability in distribution patterns align with vegetated hillslopes that are near the basin median snow depth, or along ridgelines where snow patterns appear shallow or deep depending on the ridgeline orientation. 


\section{ALS nearest peak SWE Inter-annual}
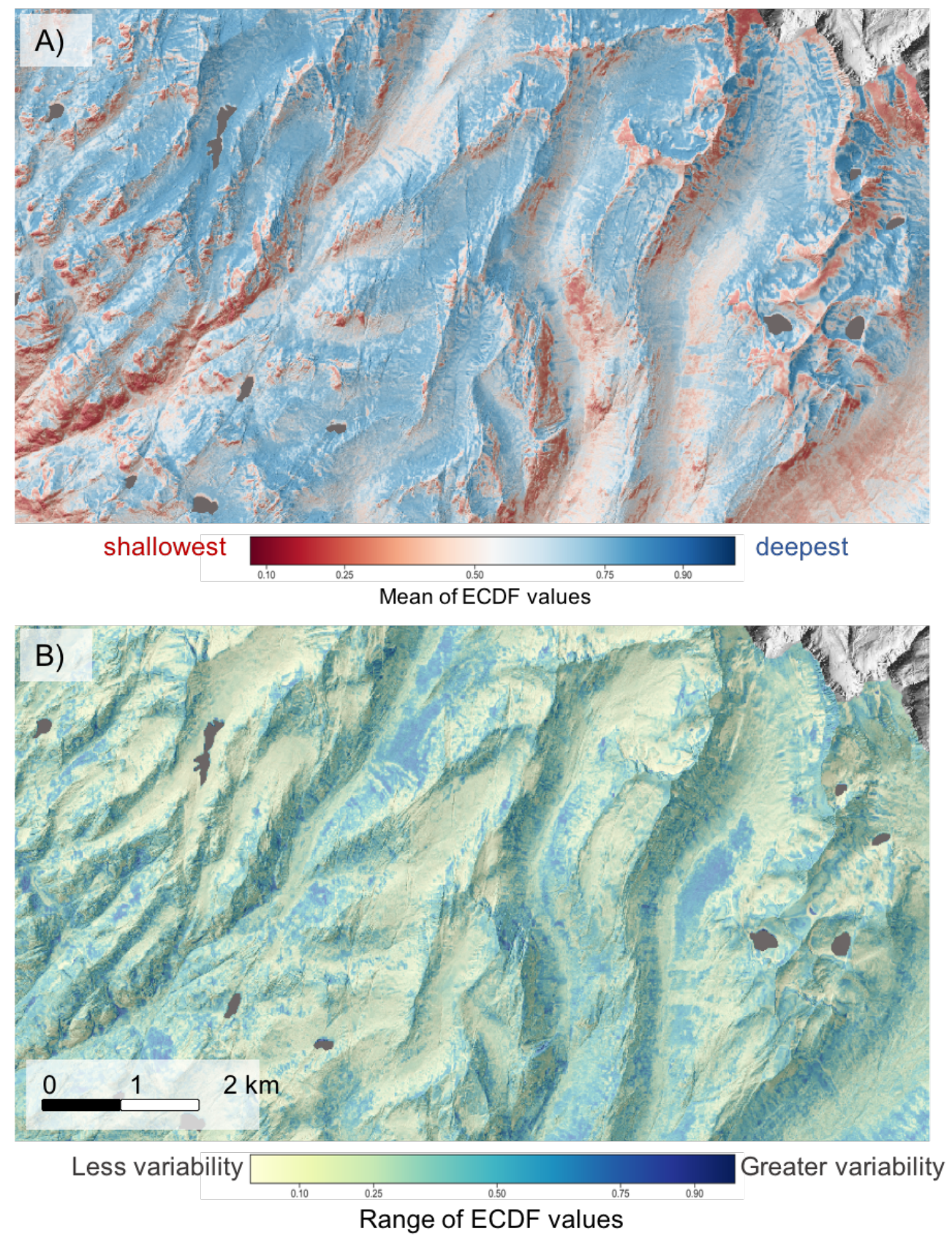

Figure 2.10: 6 ALS nearest peak SWE for an inter-annual comparison. Gray polygons are alpine lakes. (A). Mean of ECDFs show snow distribution patterns (B) Range of ECDFs show pattern consistency. 


\subsubsection{Terrain Parameters}

\section{Inter-annual 2-D Gaussian Kernel Density Estimates (KDE)}

The non-parametric quantile ranking approach mapped snow distribution patterns (mean of ECDFs) and pattern consistency (range of ECDFs) for the whole basin to provide a qualitative map of the pattern locations at high resolution. Trends were further quantified using 2-D Gaussian kernel density estimates (KDE) for terrain parameters (elevation, aspect, and slope) and the mean and range ECDF results (Figure 2.11). The $\mathrm{x}$-axis shows the frequency of a particular terrain parameter for the basin and the y-axis shows the mean ECDF values (blue) and range ECDF values (tan). The individual KDEs for each variable are on the marginal axes (top and right). The left column (mean ECDF values) shows that elevation has the most important role in snow distribution at the basin scale, compared to aspect and slope. The right column shows that the range rarely exceeds an ECDF value of 0.6, meaning it is possible that a single location experiences a shift where snow depth is below the

basin median and above the median for different years. However, there are more occurrences where a shift is near 0.2 or smaller, meaning the pattern consistency is high for that location. 


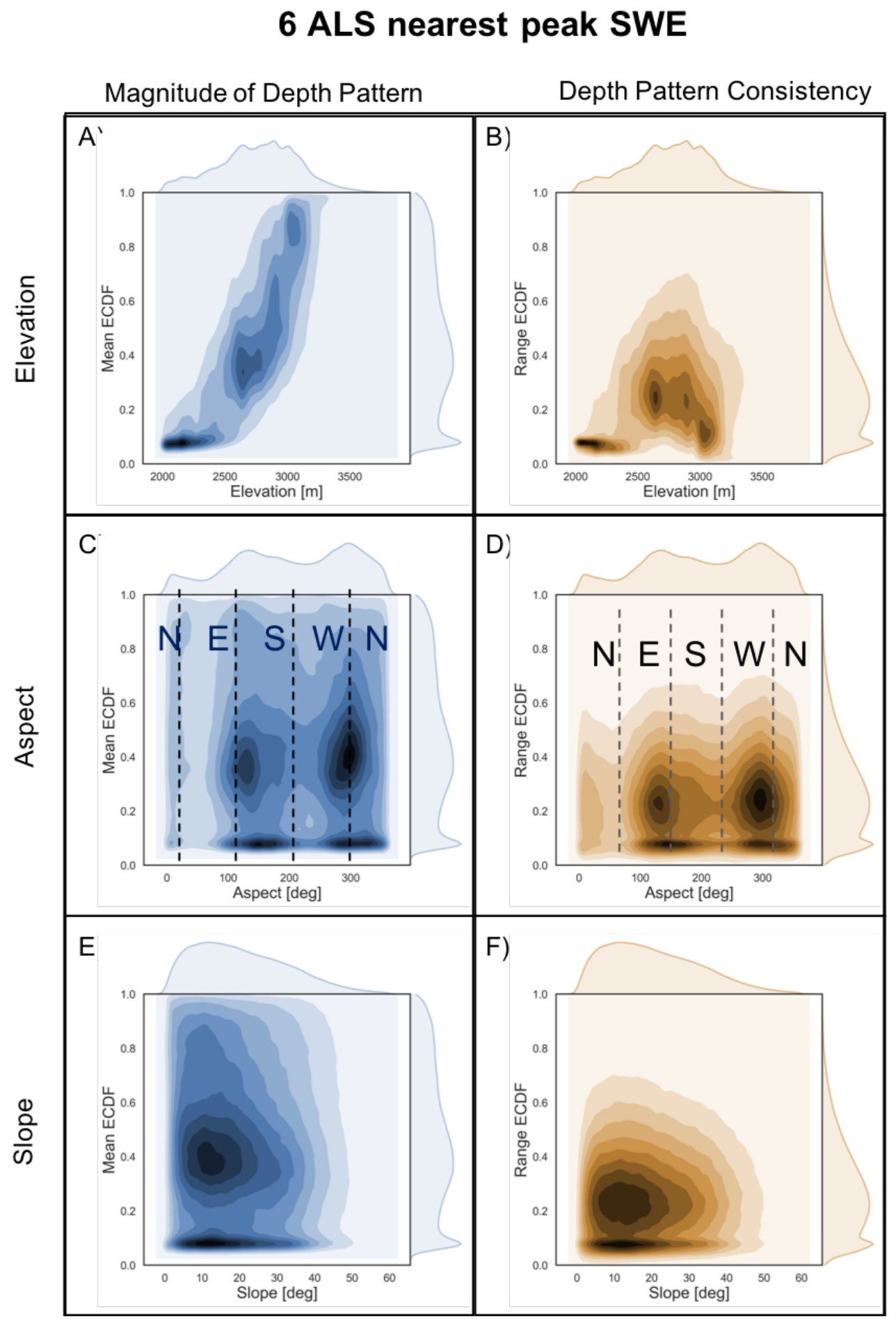

Figure 2.11: 2-D Gaussian Kernel Density Estimate (KDE) for teach terrain parameter (elevation, aspect, and slope) with the mean and range ECDF results for 6 ALS nearest peak SWE. The marginal axes (top and right) plot each respective KDE to see the individual distribution of the variable. 


\section{Feature Importance from Random Forest Classifier}

Results for the random forest classifier accuracy and feature importance for each terrain parameter are found in Table 1. Feature importance is calculated by removing each feature, running the random forest without that feature, and calculating the increase in error. Features that cause the error to significantly increase when they are not used will have a high feature importance. The results are only reported for the 6 ALS nearest peak SWE as the results were nearly identical for the 21 ALS with $\geq 80 \%$ SCA. For both the mean and range ECDF, elevation had the highest feature importance $(58 \%, 43 \%)$ for predicting snow distribution patterns and pattern consistency, respectively. Elevation was followed by aspect $(25 \%, 30 \%)$, and slope $(17 \%, 26 \%)$.

Table 2.2: Random Forest Classifier (RFC) results. Maximum tree $\operatorname{depth}=20$

Feature Importance (\%)

\begin{tabular}{cccccc}
\hline \multirow{2}{*}{ ECDF Metric } & ALS Criteria & Accuracy (\%) & Elevation & Aspect & Slope \\
mean & near peak SWE (ALS=6) & 65 & 58 & 25 & 17 \\
range & near peak SWE (ALS=6) & 67 & 43 & 30 & 26 \\
\hline
\end{tabular}

\subsection{Discussion}

\subsubsection{Inter-Annual Correlation}

In general, our results support decades of snow distribution research for large mountain basins. The significance though, comes from the rich spatio-temporal dataset leveraged to give finer detail at a large scale, as well as represent locations that typ- 
ically are too labor intensive or dangerous to collect data. For six consecutive years and 15 correlation pairs, we show high inter-annual correlation (median $r=0.79$ ) for ALS near peak SWE. This is interesting because the Tuolumne ALS dataset covers snow years that have significant departure, in both directions, from an average snow year. This initial result was key to investigating snow depth distribution patterns and determine the level of consistency for both ALS with similar snow-covered extents and near peak SWE timing.

\subsubsection{Dataset Selection for ECDF Analysis}

Using snow cover extent for ALS selection doesn't provide information on snowpack evolution, or timing of SWE in the basin; however, in this case it constrained the time window to periods where we were confident the basin didn't experience wide-spread melt events. The method could be adapted to study snow distribution patterns when the basin has significantly less snow covered area. In that case, results there would focus on patterns that occur during late-season melt at the upper elevations where radiation and sensible and latent heat exchanges contribute the most energy towards melt (Marks \& Dozier, 1992). The combination of using both snow covered area and the ALS nearest peak SWE timing shows the differences that occur when seasonal variation is mixed with year-to-year variability. Figures 2.6 and 2.7 show that the snow depth patterns persist for both ALS selections while the range of ECDF values in Figures 8 and 9 show that seasonal variation has a greater effect on the pattern consistency. 


\subsubsection{Application of Snow Distribution Patterns and Pattern Consistency Maps}

There are two primary applications for a 20-m resolution map of snow distribution patterns and pattern consistency. First, snowmelt forecasting models can benefit from knowing the depth patterns and the variability found over the terrain. The lack of robust input data and ability to adequately distribute precipitation is found to be the largest source of uncertainty when running a snowmelt model (Brauchli et al., 2017). These quantified patterns will help downscale snow model results. Secondly, the combination of maps gives quantitative reasoning to support strategic locations for new long-term monitoring sites. For example, focusing on an area with less seasonal or annual variability (yellow) Figures 2.8 - 2.9 (whole basin), and Figure 2.10 (close-up comparison), with a mixture of deep, average, and shallow zones to sample from would create a sampling strategy that represents the full basin well.

\subsubsection{Terrain Parameters}

2-D Gaussian KDEs (Figure 2.11) summarize basin-wide trends for three terrain parameters: elevation, aspect, and slope. For the mean ECDF (left column in blue) elevation has the strongest relationship. This offers a proof of concept because as elevation increases in the basin, so does snow depth (mean ECDF values: shallowest snow $=0$, deepest snow $=1$ ), with the exception of the highest mountain peaks (near vertical rock faces) in which snow depth decreases (Mott et al., 2014; Schirmer et al., 2011; Kirchner et al., 2014). The dominant aspects in the basin are southeast and west-northwest. For these dominant aspects we tend to find mean and shallow snow 
depths. At slopes between $10-15^{\circ}$ snow depths are near average and shallow depths can be found anywhere between $0-25^{\circ}$. There is not much terrain that exceeds $40^{\circ}$. The deepest snow is on the flatter slopes and not found on steep slopes.

The range ECDF (Figure 2.11, right column in tan) provides information on the consistency of snow depth patterns relative to each terrain parameter. Interestingly, there is rarely a range value greater than 0.6, meaning that for the 6 ALS near peak SWE there was never a time where snow distribution patterns exceed a $60^{\text {th }}$ percentile shift. The consistently low range values mean that 20-m ALS grid cells are commonly not changing quantile rank by more than $20 \%$. Elevations above the average rain-snow line $(2000 \mathrm{~m})$ are largely the most consistent (Roche et al., 2018). In the 2500-3000 $\mathrm{m}$ the range varies closer to the $50^{\text {th }}$ percentile, but trends towards consistent at the upper end of that elevation band. For the aspect directions that dominate the basin (SE and W-NW) snow distribution patterns are all below 0.5 ECDF range value. There is a wide range of slopes, $\sim 5-25^{\circ}$, that have consistent snow depth patterns due to the small range in ECDF values, compared to the $10-20^{\circ}$ slope band that varies more, but not more than the $50^{\text {th }}$ percentiles. The random forest classifier (RFC) predicted the feature importance based on snow distribution patterns (mean of ECDFs) and pattern consistency (range of ECDFs). From the results in Table 2.2, elevation is the most significant predictor of deep vs shallow depth and consistency ( $58 \%$ for mean ECDF and $43 \%$ for range ECDF) in snow depth patterns, likely due to the effect of elevation on temperature and preferential deposition (Lehning et al., 2008; Mott et al., 2014) over a basin of this scale. 


\subsection{Conclusion}

Using the Tuolumne Basin ALS snow depth time series dataset at 20-m resolution we show snow distribution trends for an entire large mountain basin. The basin has high inter-annual correlation (median $r=0.79$ ) when ALS are compared near peak SWE timing. This study also mapped the snow distribution patterns and pattern consistency for 21 ALS with similar snow cover extent and 6 ALS near peak SWE. Quantile ranks of snow depth distributions show that the basin has repeat patterns for consistently deep, average and shallow snow zones, independent of the snow year. Pattern consistency maps show that there is less variation in the pattern of snow depth near peak SWE across years, than with similar snow covered areas throughout a given year.

For a basin of this scale, elevation plays the most important role in snow distribution compared to aspect and slope, when studied near peak SWE. Snow distribution pattern maps show a general trend of consistently deeper snow at upper elevations and consistently shallower snow at lower elevations. More specifically, the 20-m resolution provides high-resolution detail of the average snow distribution patterns for the entire basin. Snow distribution maps can both be used to distribute forcing data in snow models and inform strategic locations for new long-term monitoring stations, as well as assess current stations for basin-wide context. Inevitably, identifying trends at the large basin scale does not account for a number of other factors (such as wind and vegetation) that are known to influence snow depth distribution. Sub region analyses at a finer ALS resolution are part of the next chapter. 


\section{CHAPTER 3:}

\section{LOCAL DEVIATIONS FROM MEAN SNOW} DEPTH AT THE SUBBASIN SCALE:

\section{VISUALIZING INTER-AND INTRA-ANNUAL PATTERNS}

\subsection{Introduction}

Seasonal snow-covered areas are vital to water resources, especially in the western US. Industry, agriculture, domestic demand, and natural ecosystems rely on the seasonal availability of water, which is made available by snowmelt from mountain reservoirs. Snowmelt water serves over 1.2 billion people, or one sixth of the world's population (Barnett et al., 2005). Forecasting water availability is dependent on our ability to accurately estimate snowpack storage. Due to spatial-temporal variability in snow and limited full coverage datasets, estimates are challenging to constrain (e.g. Elder et al., 1991; Luce et al., 1998; Elder et al., 2009; Grünewald et al., 2010; Winstral \& Marks, 2014) and uncertainties in forecasts will increase significantly in a changing climate (e.g. McCabe et al., 2007; Ye et al., 2008; Lute \& Abatzoglou, 2014; Cohen et al., 2015) Despite uncertainties at the global scale, incremental advancements in remote sensing data products and representation of physical processes at the basin 
scale are improving streamflow and snowmelt models.

Regionally isolated efforts have been successful in measuring the spatial distribution of snow using lidar-derived snow depth products (e.g. Deems et al., 2008; Trujillo et al., 2007, 2009; Grünewald et al., 2010; Tinkham et al., 2014; Harpold et al., 2015). Airborne Lidar Surveys (ALS) are costly and weather dependent, limiting the potential to make data products operationally feasible, but have provided an unmatched ability to measure snow depth at high resolution $(1-3 \mathrm{~m})$. The Tuolumne Basin, a granite-dominated alpine watershed in the Sierra Nevada, California, USA has had repeat basin-wide snow depth measurements for six years. This spatio-temporal dataset offers unparalleled information regarding the snow depth distribution and its evolution. Timing of spring melt is influenced by the thickness and spatial distribution of the snow cover (Grünewald et al., 2010), along with localized weather conditions. And, given that an alpine basin such as Tuolumne relies on snowmelt to contribute roughly $70 \%$ of total seasonal discharge (Stewart et al., 2004), the 3-m ALS dataset should be fully examined for spatial distribution patterns. Knowing when and where snow has consistent patterns, and to what extent the patterns vary year-to-year, and within a given year, will bolster high resolution modeling approaches when data are limited or non-existent, and will allow more efficient targeted ALS.

Although we set out to identify spatial patterns, the methods used in this chapter are focused on determining the consistency of the magnitude and scale of spatial patterns at select sub regions across time. Whereas, the previous chapter we investigated whole basin trends to categorically rank the consistency of spatial patterns by the cumulative distribution position with respect to the median snow depth. 


\subsection{Study Area}

Two sub regions within the Tuolumne Basin in the Sierra Nevada in Eastern California were investigated for this analysis. The first is Dana Meadows, a large roadside hummocky meadow located on the eastern end of the basin (Figure 3.1). This sub region is $1-\mathrm{km}^{2}$, the mean elevation is $2990 \mathrm{~m}$, and it has a permanent meteorological station maintained by the National Park Service. Located in the middle of the site is the Dana Fork, one of two forks that comprise the Tuolumne River, which flows south as it migrates through old glacial deposits overlain by metavolcanic and metasedimentary rock, much different than that of the otherwise granite dominated basin. Soils average 1-m or less, with maximum depths in the flatter portions reaching up to 5-m (Lowry et al., 2011). This small sub region has little variation in slope or aspect, aside from the undulating glacial deposits. Areas adjacent to the meadow are vegetated by medium density conifer groves.

The second site is referred to as Acker Peak and Meadow and is larger at $3-\mathrm{km}^{2}$ (Figure 3.2). This subregion is in the northwest corner of the basin. The elevation ranges from 2800-3200 m, evenly splitting the average elevation of Dana Meadows. The Acker site has both a flat meadow with a sinuous creek and high elevation granite peaks, giving it a broader range of aspect and slope complexity. East and west facing aspects dominate the hillslope features, while steep cliffs and bedrock fractures are dominantly north and south facing. Vegetation is constrained to the meadow edges and hillslope areas, with less than 50\% coverage. Overall the subregion has increased terrain complexity, offering a more diverse range of elevation, aspect, slope, and surface features (e.g. exposed bedrock with cliff faces, granite talus piles) when compared to Dana Meadows. 


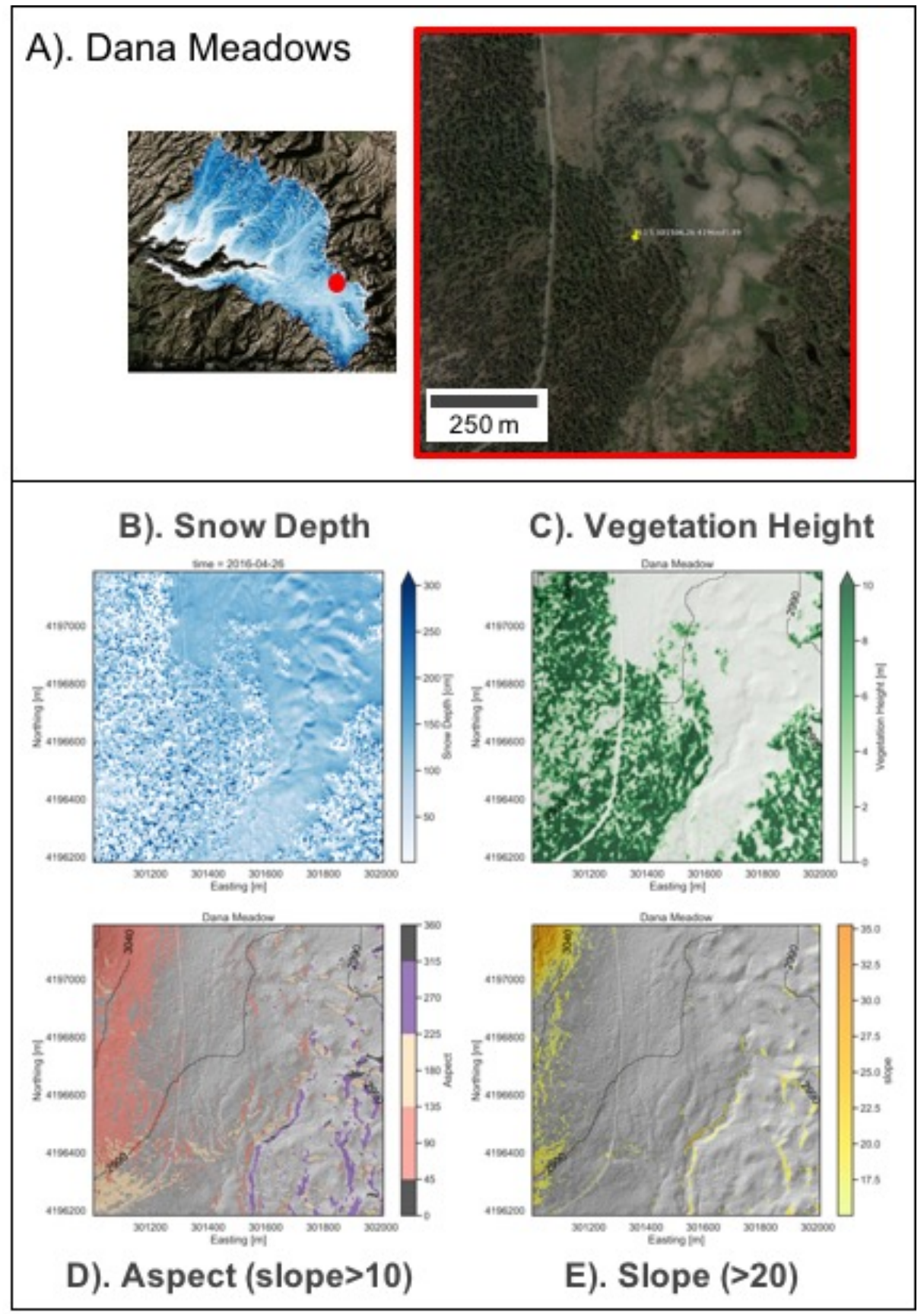

Figure 3.1: (A) Dana Meadows $\left(1-\mathrm{km}^{2}\right)$ on the east side of Tuolumne Basin with a mean elevation of 2,290 m. (B) 3-m Snow Depth product from single ALS, 26 April 2016 (one of fifty-one). (C) Vegetation height in meadow and canopy. (D) Aspect where slope is $\geq 20^{\circ}$. (E) Slopes $>20^{\circ}$. 


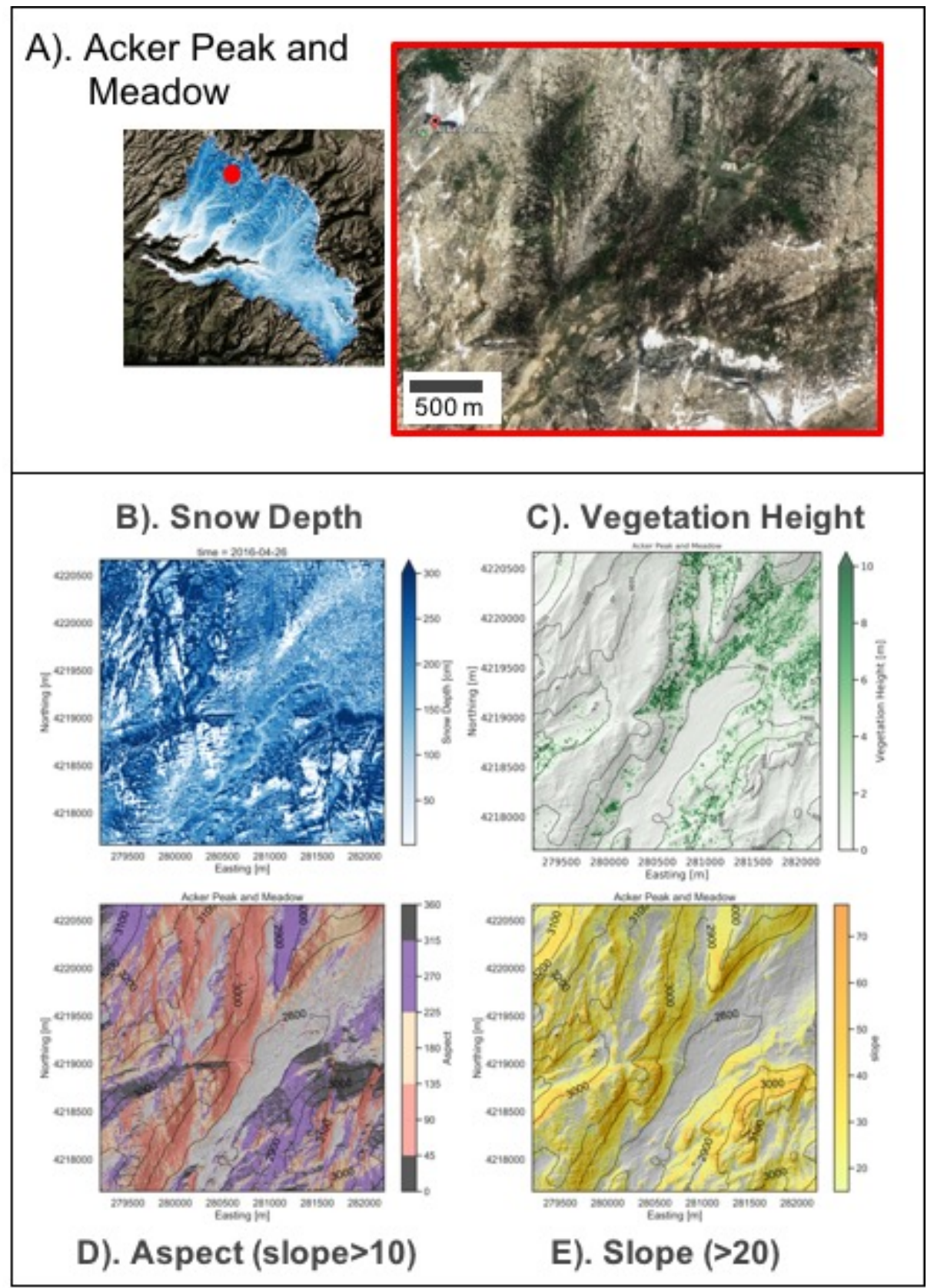

Figure 3.2: (A) Acker Peak and Meadow (3- $\left.\mathrm{km}^{2}\right)$ in the north of Tuolumne Basin with an elevation span of 2800-3200 m. (B) 3-m snow depth product from a single ALS, 26 April 2016 (one of fifty-one). (C) Vegetation height, constrained to hillslopes. (D) Aspect where slope is $\geq 20^{\circ}$. (E) Slopes $>20^{\circ}$. 


\subsection{Background and Methodology}

Both in-situ and remote sensing measurements have shown that snow depth is spatial and temporally heterogeneous regardless of watershed size and snow climate type (e.g. Elder et al., 1991; Blöschl, 1999; Baldocchi et al., 2019; Winstral \& Marks, 2002; Pomeroy et al., 2003; Erickson et al., 2005; Trujillo et al., 2007, 2009; Mott et al., 2010; Dadic et al., 2010). The 3-m airborne lidar survey (ALS) product produced by the Airborne Snow Observatory (ASO) is leveraged to study the spatial variations of snow depth through a series of distinct snow seasons (Painter, 2018b). The ALS dataset in Tuolumne Basin spans periods of drought (2013-15, including a historical drought in 2015 ( $34 \%$ of normal), two near average snow years $(2016,2018)$, and a historically large water year, 2017 ( $209 \%$ of normal). At the 3-m resolution, natural terrain features such as creeks, undulating vegetation-free meadows, and ridge lines are easily distinguishable, and even the roadways when they become snow-free or plowed are discernible. To evaluate the consistency of snow depth patterns, we chose an approach where spatial patterns would be contrasted through time. The approach selected was to remove the 'local' snow depth mean from each grid cell of the 3-m ALS product. The local snow depth mean was generated through convolution using a 150m moving window gaussian kernel. Due to the high spatial autocorrelation determined by Currier \& Lundquist (2018), a kernel size of 150-m was used, well above the 25-m correlation length found from variogram analysis (Currier \& Lundquist, 2018). While the kernel size of $150-\mathrm{m}$ is greater than five times the average correlation length found in the basin, it is of a similar or lower range of what some satellite products offer. Removing the local mean gives the residual snow depth values, highlighting the deep and shallow areas. Negative residuals are where the grid cell is below the 
local mean (relatively shallow), $0 \mathrm{~cm}$ residuals are where the grid cell value was equal to the mean snow depth within $75 \mathrm{~m}$ in every direction of the cell (half the kernel size), and residuals greater than zero are where the grid cell is above the local mean (relatively deep). Studying the residual snow depths is akin to the perspective seen during the melt season when deep areas remain snow covered, while initially shallow locations become snow-free; the stark contrast between bare ground and snow cover becomes easily spotted over the landscape. Due to the large spatio-temporal coverage of the ALS dataset, only a select combination of results was used to showcase the local mean analysis method. At both Dana Meadows $\left(1-\mathrm{km}^{2}\right)$ and Acker Peak and Meadow $\left(3-\mathrm{km}^{2}\right)$ we used a consistent kernel size $(150-\mathrm{m})$ to generate the local mean raster. Dana Meadows is an inter-annual (2013-2018) analysis of one ALS per year nearest the peak SWE date. Acker Peak and Meadow is an intra-annual (7 April 25 June) analysis with 5 ALS for 2016, a near average snow year in the Sierra.

\subsection{Results}

At both locations, Dana Meadows $\left(1-\mathrm{km}^{2}\right)$ and Acker Peak and Meadow $\left(3-\mathrm{km}^{2}\right)$, and for different time scales, snow depth patterns were shown to have repeatable patterns in space across multiple ALS, as shown by the residual snow depths (Figure 3.3 and $3.4)$.

\subsubsection{Inter-Annual at Dana Meadows}

At Dana Meadows, both the hummocky meadow and vegetated portion had spatial consistency in snow depth patterns for year-to-year ALS nearest basin wide peak SWE (Figure 3.3). The meadow area showed the most prevailing snow distribution patterns. Deep and shallow zones are sharply contrasted from north to south over 
the grassy hummocks. The flattest parts of the meadow are closest to the local mean, with a $0 \mathrm{~cm}$ residual. The meadow edges have consistently deeper snow zones before transitioning to shallower snow underneath the forest canopy, likely due to interception, wind transport, and increased incoming longwave radiation. Results varied at the open-forest boundary depending on what size area was selected for the local mean (see Appendix A). Forested areas with shorter scale transitions have enhanced contrast between relatively deep and shallow snowpack, which at this scale could be a combination of tree well occurrence or lidar processing artifacts. For reference, the north-south line that appears left of center is the Tioga Pass Road (Figure 3.3). The three most dissimilar snow years (2015-2017) were selected to demonstrate pattern consistency for the residual snow depths, after the local mean was removed from the 3-m grid cells (Figure 3.5). The residual snow depth magnitude, or absolute difference, between the contrasting years varies, but the spatial alignment of where snow is consistently deep, shallow, and equal to the surrounding local mean is evident across the meadow.

\subsubsection{Intra-annual at Acker Peak and Meadow}

The five scenes representing the within-year patterns of snow depth distribution show an evolution of snow depth from basin-wide peak SWE timing on towards melt for the near average 2016 snow season (Figure 4). The scenes in June have more melt and zero snow depths dominate the meadow and transitioning hillslopes. However, through this series of melt evolution scenes, spatial patterns appear consistent, especially on the hillslopes and higher elevation features. Ridgeline features show repeated patterns of shallow, likely wind scoured snow on south and west facing aspects from the synoptic southwest wind patterns off the Pacific Coast, with deeper snow deposition 
adjacent on the easterly slopes. The north side of Acker Peak (upper left) has bands of shallow and deep snow, again strongly consistent through time. The southeast knob (bottom right) has south facing chutes with shallow snowpack that gradually melts away by June. The flat areas in the meadow are more homogenous and remain close to the local mean since the residual snow depth is near $0 \mathrm{~cm}$. Overall, the scenes show depth patterns are largely similar, suggesting that the distribution patterns develop during the accumulation period and persist into the melt season. Three scenes, each roughly two months apart, were selected to demonstrate the accumulation, peak, and ablation periods for within-year variability in spatial snow depth patterns (Figure 3.6). Areas with hillslopes at higher elevation develop distinct deep and shallow zones early and are maintained through the peak and into the melt season, while flatter areas smooth to match the local mean. By June, some exposed high points trend towards the local mean with $0 \mathrm{~cm}$ residual value. Again, the within-year scenes show that snow distribution patterns are established during the accumulation period and remain until becoming snow-free. 
Inter-annual

1 ALS/yr. nearest peak SWE

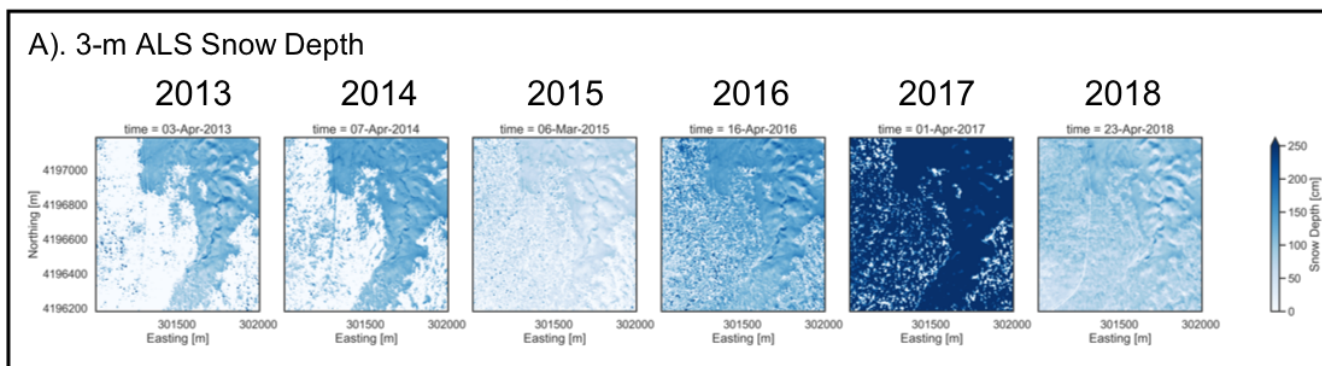

B). Local Mean Snow Depth, 150-m moving Gaussian

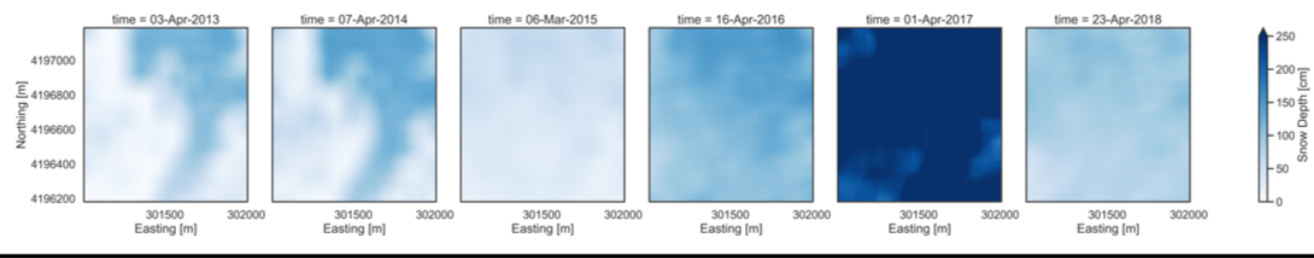

C). Residual Snow Depth (ALS snow depth - Local mean snow depth)

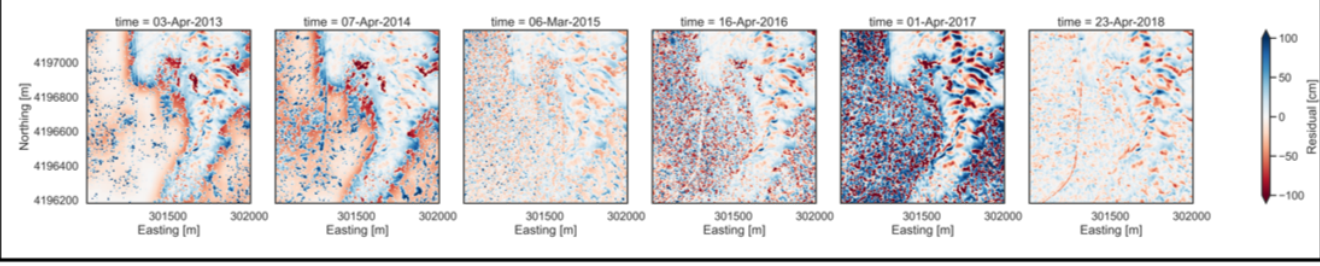

Dana Meadows $\left(1-\mathrm{km}^{2}\right)$

Figure 3.3: Dana Meadows local mean analysis. (A) ALS snow depth at 3-m resolution. One ALS per year (2013-2018) nearest peak SWE timing.(B)

Local mean snow depth generated by convolution of 150-m moving Gaussian filter. (C) Difference of A and B, or the residual snow depth [cm]. 
Intra-annual

April- June, 2016

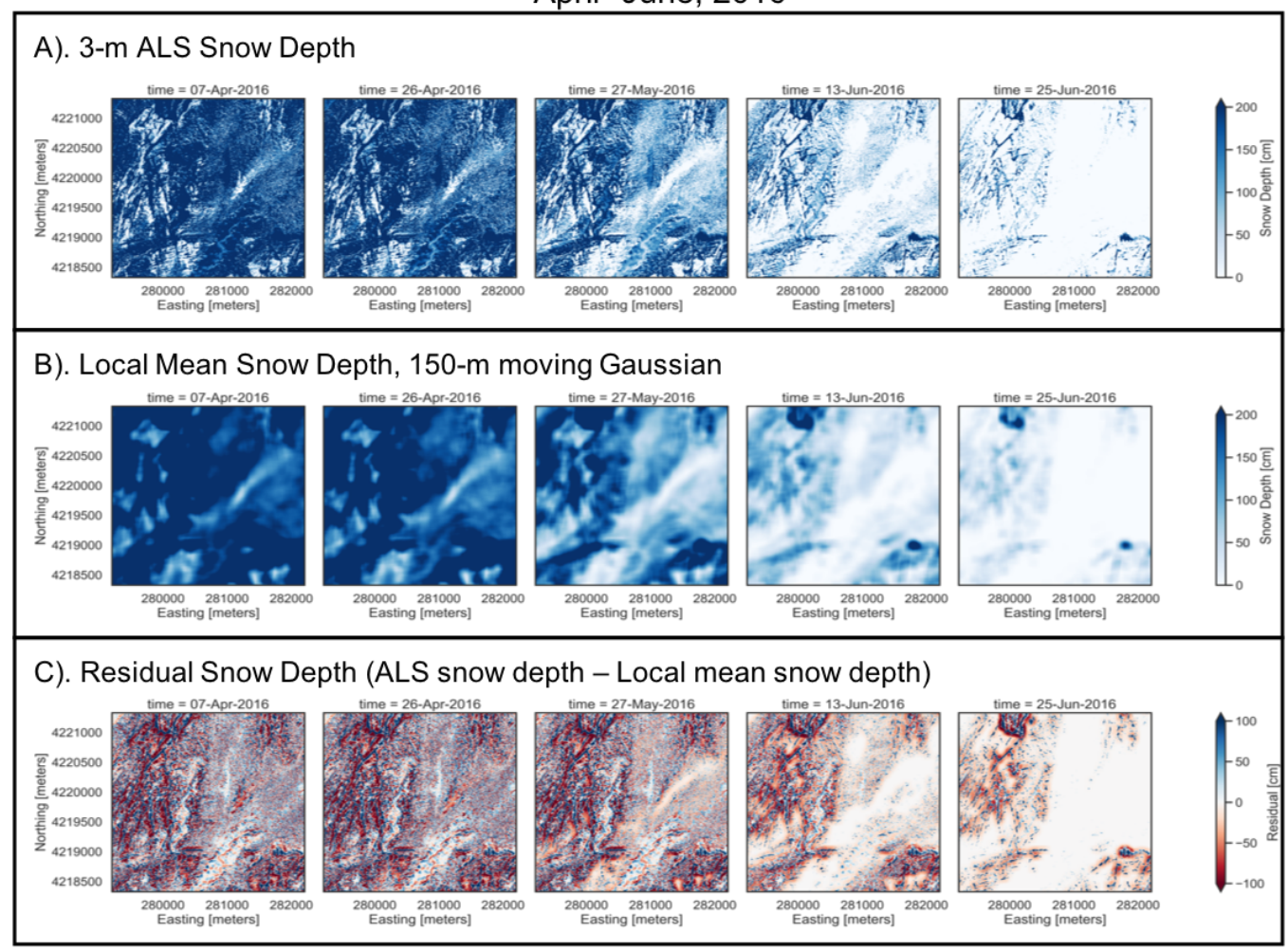

Acker Peak and Meadow (3-km²)

Figure 3.4: Acker Peak and Meadow local mean analysis. (A) ALS snow depth at 3-m resolution. ALS are from 2016 and cover April-June, intraannual. (B) Local mean snow depth generated by convolution of 150-m moving Gaussian filter. (C) Difference of A and B, or the residual snow $\operatorname{depth}[\mathrm{cm}]$. 


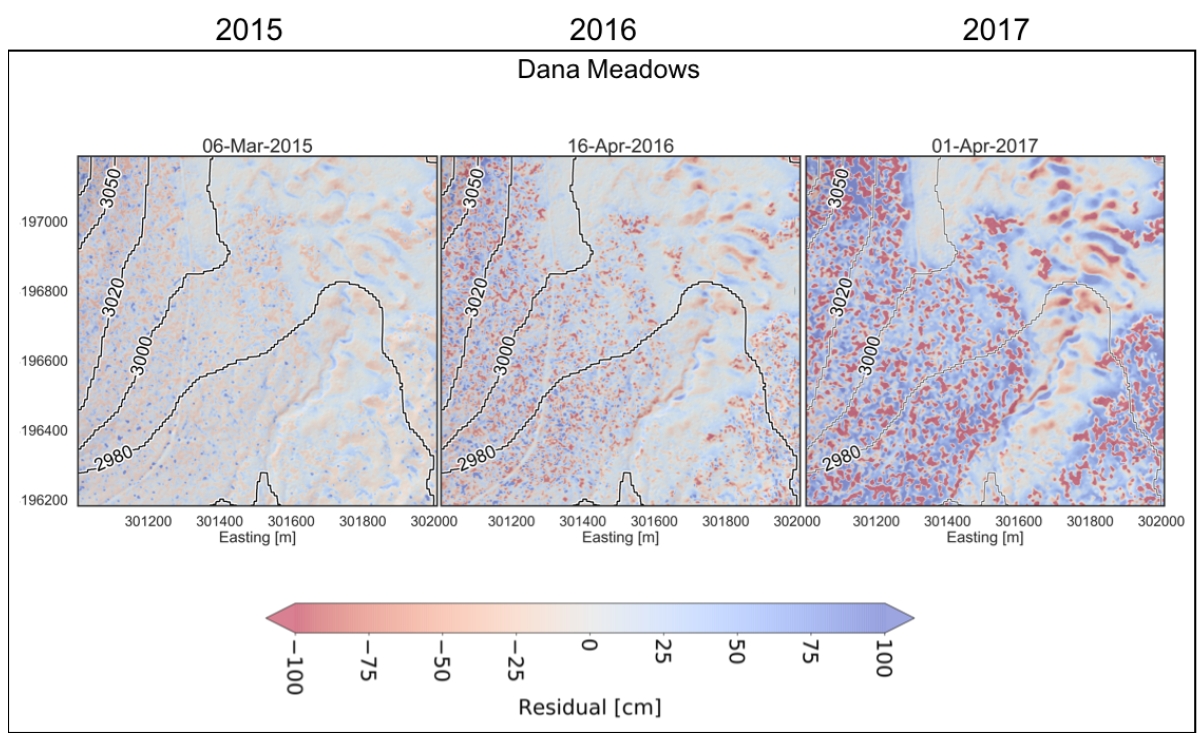

Figure 3.5: Close up of inter-annual residual snow depth patterns for the three most dissimilar snow years, 2015 (low), 2016 (near average), 2017 (high) in recent history.

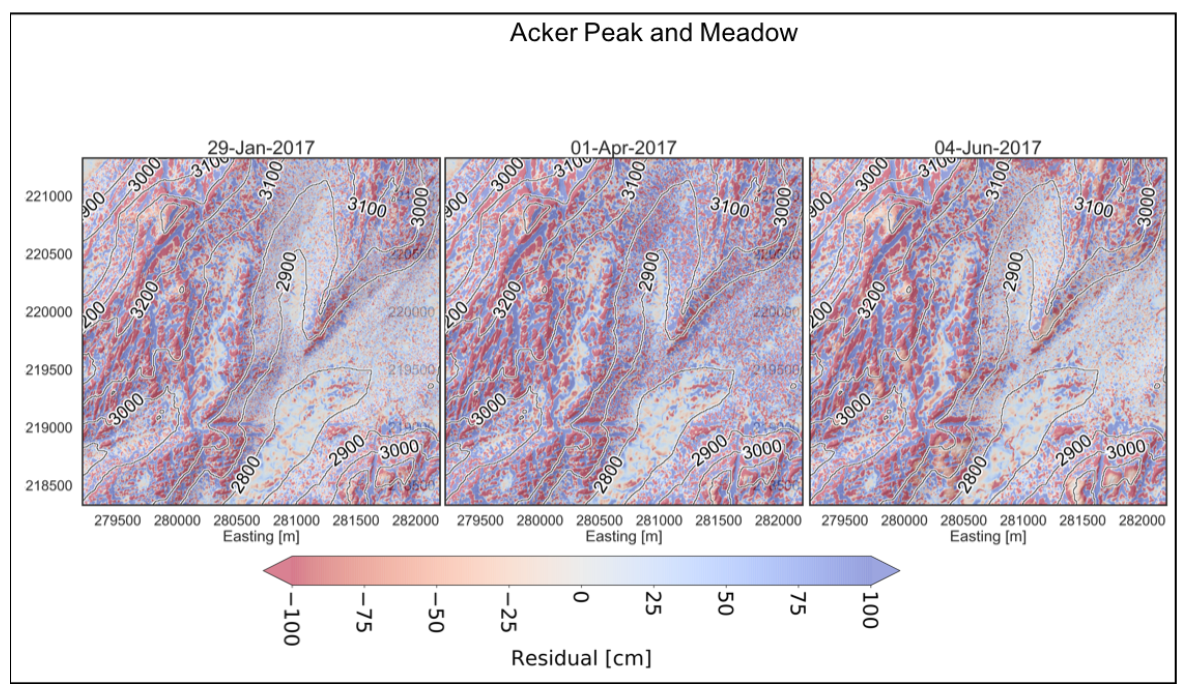

Figure 3.6: Close up of intra-annual residual snow depth patterns for the accumulation, peak and melt portions of 2017. 


\subsection{Discussion}

Investigating the residual patterns left from differencing the 150-m local snow depth mean from 3-m ALS in two sub regions of Tuolumne Basin shows promising results towards spatial pattern identification. This method could be further explored over different sub regions, catchments zones, and possibly over the basin as a whole with adequate computational resources. Moreover, additional iterations could be evaluated using different kernel sizes for the local mean evaluation, which we expect will continue to emphasize different dominant physical processes at different scales. The extent to which the kernel size was examined is described in Appendix A.

Many studies have investigated scale invariance between snow depth and physical processes (e.g. Blöschl, 1999; Deems et al., 2006, 2008; Trujillo et al., 2007, 2009; Lehning et al., 2008; Merz et al., 2009; Mott et al., 2010; Schirmer et al., 2011; Schirmer \& Lehning, 2011; Kirchner et al., 2014), but have lacked a rich dataset that is both high resolution and over a large temporal extent. From the features and topography in the $1-3-\mathrm{km}^{2}$ sub regions, several of the known factors that influence snow depth heterogeneity were identified. Factors that occur typically over larger scales (Grunewald et al., 2013) and complex topography (Tennant et al., 2017) such as elevation and aspect dependence were largely seen at the Acker site. Effects of wind redistribution and vegetation interaction from terrain features appeared at both sites and are known to occur over shorter length scales (Winstral et al., 2013; Musselman et al., 2015). Based on the locations of relative deep and shallow zones and nearby terrain features (Sturm \& Wagner, 2010) the magnitude and duration of repeat snow depth patterns is apparent. Moreover, we have determined the high-resolution patterns that result at the sub 150-m scale for a flatter, mixed open-forest region (Dana Meadows) and 
aspect-variant, steep bedrock-dominated region (Acker Peak and Meadow).

Terrain features were easily discernible at the sub 150-m scale and had repeat deep, average, and shallow zones within terrain type boundaries. For example, in Dana Meadows where the previously glaciated surface has undulating half-meter size rolling topography bounding the Dana Fork, there are alternating patches of deep and shallow snow. These patterns are nonexistent when smoothed to 150-m filter (Figure 3b); only a faint outline between the meadow and canopy coverage is identified and only for a few of the years. A coarser snow depth product (e.g. satellite or land surface model) would show a much smoother depth pattern, and could lead to snowmelt timing and peak discharge errors (Luce et al., 1998; Marks \& Winstral, 2001). Knowing that the snow distribution trends towards repeatable and discernible patterns over time, we can model those expected patterns from the coarser and generally more temporally available snow depth products.

\subsubsection{Inter-Annual at Dana Meadows}

This scene has two dominating terrain features: open meadow and adjacent forest canopy. The boundary area is identifiable in all the residual plots (Figure 3) because of the sharp contrast between deeper snow at the meadows edge and the shallow snow directly at the forest canopy edge. This pattern is evident in all scenes, but especially highlighted in 2013 and 2014. We think the meadow-canopy boundary for those two years was exaggerated due to the limited accuracy of snow depths in the forest. Performance over forested regions increased throughout the course of ALS data collection (Kostadinov et al., 2019). This is observable in the raw snow depths (Figure 3.3a) where a significant portion of the forested area has snow depth values near $0 \mathrm{~cm}$, despite the ALS being near peak SWE. 
The snow depth patterns of interest are the acutely apparent ones in the meadow. When averaged at 150-m there are no discernible deep or shallow zones, but when differenced, the residual reveals the alternating deep and shallows zones over the grassy half-meter tall rolling hummocks. Due to the short length scale (5-10m) (Dadic et al., 2010) and near peak SWE timing as opposed to mid-ablation periods, these patterns are most likely caused by wind redistribution (Winstral \& Marks, 2002). The majority of eastern Sierra storm tracks supply a southwest wind (Currier \& Lundquist, 2018) that repeatedly scours the southwest slopes and redeposits snow grains on the northeast face; this pattern is visible in these residual maps.

\subsubsection{Intra-Annual at Acker Peak and Meadow}

From the within-year example of 2016, a near average snow year (Figure 3.4), focused from peak SWE into the ablation period, we track the timing of pattern deviation for the range of features offered in this sub region. Opposing east and west ridgelines prominent at higher elevations, bare of vegetation, maintain distinct deep and shallow zones until melt dominates the scene. Similarly, the meadow (bottom center) has spatially aligned patterns before the appearance of seasonal melt. The two features described are vegetation-limited or have short, consistent grass cover, respectively, and show the most contrast between consistently deep and shallow zones. Conversely, the valley hillslopes where more pronounced vegetation exists show increased variation of spatial patterns, or patterns simply occur at a significantly smaller scale for deep and shallow zones. Spatial agreement for the residual snow depths are not desirable for the more densely vegetated areas at this $3-\mathrm{km}^{2}$ sub region. The canopy covered area is more heterogeneous compared to the vegetation-limited areas with respect to the spatial alignment of residual snow depths. Smaller sub regions may further 
constrain vegetation pattern consistencies, but at this scale, it is likely a combination of snow deposition changing the forest canopy (weighing down full tree limbs, and small nimble tree trunks) or that ALS performance decreased in denser canopy.

The example of within-year spatial patterns (Figure 3.6) gives insight into the value of additional ALS collections, by looking at the intra-annual persistence of depth patterns. We know that spatial distribution of snow depth affects melt timing (Luce et al., 1998) and overall discharge (Marks \& Winstral, 2001). If spatial patterns are most distinct prior or near peak SWE, that information could be used in a hydrologic model. Given the snow depth distribution at peak SWE, varied decay rates for snowmelt processes could occur at the different terrain features. For this intra-annual scenario (Figure 3.6), the lowest elevation with minimal slope (flat ground) would decay at the quickest rate, while the steep hillslopes, predominately north-facing at elevation would have the slowest decay rate to melt snow.

\subsection{Conclusion}

Residual snow depths show consistent spatial patterns of snow distribution, both on inter- and intra-annual timescales for sub regions of Tuolumne Basin. Residual snow depths patterns are developed in the accumulation season and persist through the melt period. Vegetation-limited areas (open meadows and bedrock dominated terrain) have more pronounced consistently deep, shallow, and average zones. While the patterns of the residuals are consistent, the magnitude increases with mean snow depth.

At Dana Meadows, the snow distribution patterns of the pronounced deep and shallow zones occur on a scale that matches wind redistribution. Although residual snow depths differ in magnitude, the high spatial agreement is independent of the 
snow year. At the Acker site, the intra-annual comparison over a larger and more topographically dynamic area shows snow distribution patterns are spatially aligned, but the duration of the pattern is dependent on the location and extent of the residual snow depth values. The higher the elevation and flatter the terrain, the more persistent the residual patterns are, until grid cells become snow-free. Valley hillslopes have repeated snow distribution patterns, but not to the extent of the large residual deep bands on the north and east facing ridgelines.

Our fine-scale study of repeat pattern identification has encouraging initial results and should be further explored to use the full collection of available ALS data. The magnitude of snow distribution patterns and temporal duration of an expected can be characterized for a season from the residual snow depth values. The best application is for high-resolution snow distribution patterns to be applied to the precipitation forcing data as a way to accurately distribute snow on a modeled land surface and to better inform the location of manual snow observations. 


\author{
Abbreviations \\ ALS Airborne Lidar Survey \\ ASO Airborne Snow Observatory \\ LIDAR Light Detection and Ranging \\ $T L S$ Terrestrial Laser Scans \\ MODIS Moderate Resolution Imaging Spectroradiometer \\ GPS Global Positioning System \\ $I M U$ Inertial Measurement Units \\ SWE Snow Water Equivalent \\ $S C A$ Snow Covered Areas \\ NRCS National Resource Conservation Service \\ USDA-ARS-NWRC United States Department of Agricultural-Agricultural Research \\ Service-Northwest Watershed Research Center \\ $R M S D$ Root Mean Square Difference \\ $R$ Correlation Coefficient \\ SDV Standardized Depth Values \\ KDE Kernel Density Estimate \\ ECDF Empirical Cumulative Distribution Function \\ RFC Random Forest Classifier
}




\section{REFERENCES}

Ackermann, Friedrich. 1999. Airborne laser scanning: present status and future expectations. ISPRS Journal of Photogrammetry and Remote sensing, 54(2-3), 64-67.

Bair, Edward H, Davis, Robert E, \& Dozier, Jeff. 2018. Hourly mass and snow energy balance measurements from Mammoth Mountain, CA USA, 2011-2017. Earth System Science Data, 10(1), 549-563.

Baldocchi, Dennis, Dralle, David, Jiang, Chongya, \& Ryu, Youngryel. 2019. How much water is evaporated across California? A multiyear assessment using a biophysical model forced with satellite remote sensing data. Water Resources Research, 55(4), 2722-2741.

Barnett, Tim P, Adam, Jennifer C, \& Lettenmaier, Dennis P. 2005. Potential impacts of a warming climate on water availability in snow-dominated regions. Nature, 438(7066), 303-309.

Blöschl, Günter. 1999. Scaling issues in snow hydrology. Hydrological processes, 13(14-15), 2149-2175.

Brauchli, Tristan, Trujillo, Ernesto, Huwald, Hendrik, \& Lehning, Michael. 2017. Influence of slope-scale snowmelt on catchment response simulated with the Alpine3D model. Water Resources Research, 53(12), 10723-10739. 
Brucker, Ludovic, Hiemstra, Christopher, Marshall, Hans-Peter, Elder, Kelly, De Roo, Roger, Mousavi, Mohammad, Bliven, Francis, Peterson, Walt, Deems, Jeffrey, Gadomski, Peter, et al. 2017. A first overview of SnowEx ground-based remote sensing activities during the winter 2016-2017. Pages 1391-1394 of: 2017 IEEE International Geoscience and Remote Sensing Symposium (IGARSS). IEEE.

Cline, Don, Yueh, Simon, Chapman, Bruce, Stankov, Boba, Gasiewski, Al, Masters, Dallas, Elder, Kelly, Kelly, Richard, Painter, Thomas H, Miller, Steve, et al. 2009. NASA cold land processes experiment (CLPX 2002/03): Airborne remote sensing. Journal of Hydrometeorology, 10(1), 338-346.

Cohen, Judah, Ye, Hengchun, \& Jones, Justin. 2015. Trends and variability in rainon-snow events. Geophysical Research Letters, 42(17), 7115-7122.

Cristea, Nicoleta C, Lundquist, Jessica D, Loheide, Steven P, Lowry, Christopher S, \& Moore, Courtney E. 2014. Modelling how vegetation cover affects climate change impacts on streamflow timing and magnitude in the snowmelt-dominated upper Tuolumne Basin, Sierra Nevada. Hydrological processes, 28(12), 3896-3918.

Currier, William Ryan, \& Lundquist, Jessica D. 2018. Snow depth variability at the forest edge in multiple climates in the western United States. Water Resources Research, 54(11), 8756-8773.

Currier, William Ryan, Pflug, Justin, Mazzotti, Giulia, Jonas, Tobias, Deems, Jeffrey S, Bormann, Kat J, Painter, Thomas H, Hiemstra, Christopher A, Gelvin, Arthur, Uhlmann, Zach, et al. 2019. Comparing aerial lidar observations with terrestrial lidar and snow-probe transects from NASA's 2017 SnowEx campaign. Water Resources Research, 55(7), 6285-6294. 
Dadic, R, Mott, R, Lehning, M, \& Burlando, Paolo. 2010. Parameterization for wind-induced preferential deposition of snow. Hydrological Processes, 24(14), 1994-2006.

Deems, Jeffrey S, \& Painter, Thomas H. 2006. Lidar measurement of snow depth: accuracy and error sources. Pages 330-338 of: Proceedings of the 2006 International Snow Science Workshop: Telluride, Colorado, USA, International Snow Science Workshop.

Deems, Jeffrey S, Fassnacht, Steven R, \& Elder, Kelly J. 2006. Fractal distribution of snow depth from LiDAR data. Journal of Hydrometeorology, 7(2), 285-297.

Deems, Jeffrey S, Fassnacht, Steven R, \& Elder, Kelly J. 2008. Interannual consistency in fractal snow depth patterns at two Colorado mountain sites. Journal of Hydrometeorology, 9(5), 977-988.

Deems, Jeffrey S, Painter, Thomas H, \& Finnegan, David C. 2013. Lidar measurement of snow depth: a review. Journal of Glaciology, 59(215), 467-479.

Elder, Kelly, Dozier, Jeff, \& Michaelsen, Joel. 1991. Snow accumulation and distribution in an alpine watershed. Water Resources Research, 27(7), 1541-1552.

Elder, Kelly, Cline, Don, Liston, Glen E, \& Armstrong, Richard. 2009. NASA Cold Land Processes Experiment (CLPX 2002/03): Field measurements of snowpack properties and soil moisture. Journal of Hydrometeorology, 10(1), 320-329.

Erickson, Tyler A, Williams, Mark W, \& Winstral, Adam. 2005. Persistence of topographic controls on the spatial distribution of snow in rugged mountain terrain, Colorado, United States. Water Resources Research, 41(4). 
Famiglietti, James S, Lo, Minhui, Ho, Sing L, Bethune, James, Anderson, KJ, Syed, Tajdarul H, Swenson, Sean C, de Linage, Caroline R, \& Rodell, Matthew. 2011. Satellites measure recent rates of groundwater depletion in California's Central Valley. Geophysical Research Letters, 38(3).

Ferraz, António, Saatchi, Sassan, Bormann, Kat J, \& Painter, Thomas H. 2018. Fusion of NASA Airborne Snow Observatory (ASO) lidar time series over mountain forest landscapes. Remote Sensing, 10(2), 164.

Garen, David C, \& Marks, Danny. 2005. Spatially distributed energy balance snowmelt modelling in a mountainous river basin: estimation of meteorological inputs and verification of model results. Journal of Hydrology, 315(1-4), 126-153.

Grünewald, T, Schirmer, M, Mott, R, \& Lehning, Michael. 2010. Spatial and temporal variability of snow depth and SWE in a small mountain catchment. The Cryosphere, 4(ARTICLE), 215-225.

Grunewald, T, Stotter, J, Pomeroy, John W, Dadic, Ruzica, Baños, I Moreno, Marturià, J, Sproß, Maximilian, Hopkinson, Christopher, Burlando, Paolo, \& Lehnig, M. 2013. Statistical modelling of the snow depth distribution in open alpine terrain.

Harpold, Adrian A, Marshall, Jill A, Lyon, Steve W, Barnhart, TB, Fisher, BA, Donovan, M, Brubaker, KM, Crosby, CJ, Glenn, Nancy F, Glennie, CL, et al. 2015. Laser vision: lidar as a transformative tool to advance critical zone science.

Hedrick, Andrew R, Marks, Danny, Havens, Scott, Robertson, Mark, Johnson, Micah, Sandusky, Micah, Marshall, Hans-Peter, Kormos, Patrick R, Bormann, Kat J, \& 
Painter, Thomas H. 2018. Direct insertion of NASA Airborne Snow Observatoryderived snow depth time series into the iSnobal energy balance snow model. Water Resources Research, 54(10), 8045-8063.

Henn, Brian, Painter, Thomas H, Bormann, Kat J, McGurk, Bruce, Flint, Alan L, Flint, Lorraine E, White, Vince, \& Lundquist, Jessica D. 2018. High-elevation evapotranspiration estimates during drought: Using streamflow and NASA Airborne Snow Observatory SWE observations to close the Upper Tuolumne River Basin water balance. Water Resources Research, 54(2), 746-766.

Hopkinson, Chris, Sitar, Mike, Chasmer, Laura, Gynan, Chris, Agro, David, Enter, Robert, Foster, James, Heels, Nicole, Hoffman, Crystal, Nillson, Jeff, et al. 2001. Mapping the spatial distribution of snowpack depth beneath a variable forest canopy using airborne laser altimetry. Pages 253-264 of: Proceedings of the 58th Eastern Snow Conference, Ottawa, Ontario, Canada: USA, Eastern Snow Conference.

Hopkinson, Chris, Sitar, Mike, Chasmer, Laura, \& Treitz, Paul. 2004. Mapping snowpack depth beneath forest canopies using airborne lidar. Photogrammetric Engineering 85 Remote Sensing, 70(3), 323-330.

Hopkinson, Chris, Pomeroy, John, Debeer, Chris, Ellis, Chad, \& Anderson, Axel. 2012. Relationships between snowpack depth and primary LiDAR point cloud derivatives in a mountainous environment. IAHS-AISH publication, 354-358.

Hoyer, Stephan, \& Hamman, Joe. 2017. xarray: ND labeled arrays and datasets in Python. Journal of Open Research Software, 5(1). 
Kaula, WM, Schubert, G, Lingenfelter, RE, Sjogren, WL, \& Wollenhaupt, WR. 1973. Lunar topography from Apollo 15 and 16 laser altimetry. Page 2811 of: Lunar and Planetary Science Conference Proceedings, vol. 4.

Kirchner, PB, Bales, RC, Molotch, NP, Flanagan, J, \& Guo, Q. 2014. LiDAR measurement of seasonal snow accumulation along an elevation gradient in the southern Sierra Nevada, California. Hydrology $\&$ Earth System Sciences, 18(10).

Kostadinov, Tihomir S, Schumer, Rina, Hausner, Mark, Bormann, Kat J, Gaffney, Rowan, McGwire, Kenneth, Painter, Thomas H, Tyler, Scott, \& Harpold, Adrian A. 2019. Watershed-scale mapping of fractional snow cover under conifer forest canopy using lidar. Remote Sensing of Environment, 222, 34-49.

Lehning, M, Löwe, H, Ryser, M, \& Raderschall, N. 2008. Inhomogeneous precipitation distribution and snow transport in steep terrain. Water Resources Research, 44(7).

Lowry, Christopher S, Loheide, Steven P, Moore, Courtney E, \& Lundquist, Jessica D. 2011. Groundwater controls on vegetation composition and patterning in mountain meadows. Water Resources Research, $\mathbf{4 7}(10)$.

Luce, Charles H, Tarboton, David G, \& Cooley, Keith R. 1998. The influence of the spatial distribution of snow on basin-averaged snowmelt. Hydrological Processes, 12(10-11), 1671-1683.

Lundquist, Jessica D, Roche, James W, Forrester, Harrison, Moore, Courtney, Keenan, Eric, Perry, Gwyneth, Cristea, Nicoleta, Henn, Brian, Lapo, Karl, McGurk, Bruce, et al. 2016. Yosemite H ydroclimate N etwork: Distributed stream 
and atmospheric data for the $\mathrm{T}$ uolumne $\mathrm{R}$ iver watershed and surroundings. Water Resources Research, 52(9), 7478-7489.

Lute, AC, \& Abatzoglou, JT. 2014. Role of extreme snowfall events in interannual variability of snowfall accumulation in the western United States. Water Resources Research, 50(4), 2874-2888.

Marks, Danny, \& Dozier, Jeff. 1992. Climate and energy exchange at the snow surface in the alpine region of the Sierra Nevada: 2. Snow cover energy balance. Water Resources Research, 28(11), 3043-3054.

Marks, Danny, \& Winstral, Adam. 2001. Comparison of snow deposition, the snow cover energy balance, and snowmelt at two sites in a semiarid mountain basin. Journal of Hydrometeorology, 2(3), 213-227.

Marks, Danny, Domingo, James, Susong, Dave, Link, Tim, \& Garen, David. 1999. A spatially distributed energy balance snowmelt model for application in mountain basins. Hydrological processes, 13(12-13), 1935-1959.

Mazzotti, Giulia, Currier, William Ryan, Deems, Jeffrey S, Pflug, Justin M, Lundquist, Jessica D, \& Jonas, Tobias. 2019. Revisiting snow cover variability and canopy structure within forest stands: Insights from airborne lidar data. $W a-$ ter Resources Research, 55(7), 6198-6216.

McCabe, Gregory J, Clark, Martyn P, \& Hay, Lauren E. 2007. Rain-on-snow events in the western United States. Bulletin of the American Meteorological Society, 88(3), $319-328$. 
Merz, R, Parajka, J, \& Blöschl, G. 2009. Scale effects in conceptual hydrological modeling. Water resources research, 45(9).

Mott, Rebecca, Schirmer, Michael, Bavay, M, Grünewald, T, \& Lehning, M. 2010. Understanding snow-transport processes shaping the mountain snow-cover. The Cryosphere, 4(4), 545.

Mott, Rebecca, Scipión, Danny, Schneebeli, Marc, Dawes, Nicholas, Berne, Alexis, \& Lehning, Michael. 2014. Orographic effects on snow deposition patterns in mountainous terrain. Journal of Geophysical Research: Atmospheres, 119(3), 1419-1439.

Musselman, Keith N, Pomeroy, John W, Essery, Richard LH, \& Leroux, Nicolas. 2015. Impact of windflow calculations on simulations of alpine snow accumulation, redistribution and ablation. Hydrological Processes, 29(18), 3983-3999.

Painter, Thomas H. 2018a. ASO L4 Lidar Snow Depth 3m UTM Grid, Version 1. National Snow and Ice Data Center, Grand Mesa, Feb-2017.

Painter, Thomas H. 2018b. ASO L4 Lidar Snow Depth 3m UTM Grid, Version 1. National Snow and Ice Data Center, Tuolumne Basin, Apr-2013 - May-2018.

Painter, Thomas H, Berisford, Daniel F, Boardman, Joseph W, Bormann, Kathryn J, Deems, Jeffrey S, Gehrke, Frank, Hedrick, Andrew, Joyce, Michael, Laidlaw, Ross, Marks, Danny, et al. 2016. The Airborne Snow Observatory: Fusion of scanning lidar, imaging spectrometer, and physically-based modeling for mapping snow water equivalent and snow albedo. Remote Sensing of Environment, 184, 139-152.

Pomeroy, JW, Toth, B, Granger, RJ, Hedstrom, NR, \& Essery, RLH. 2003. Variation 
in surface energetics during snowmelt in a subarctic mountain catchment. Journal of Hydrometeorology, 4(4), 702-719.

Reutebuch, Stephen E, McGaughey, Robert J, Andersen, Hans-Erik, \& Carson, Ward W. 2003. Accuracy of a high-resolution lidar terrain model under a conifer forest canopy. Canadian journal of remote sensing, 29(5), 527-535.

Rice, Robert, Bales, Roger C, Painter, Thomas H, \& Dozier, Jeff. 2011. Snow water equivalent along elevation gradients in the Merced and Tuolumne River basins of the Sierra Nevada. Water Resources Research, $\mathbf{4 7}(8)$.

Roche, James W, Bales, Roger C, Rice, Robert, \& Marks, Danny G. 2018. Management Implications of Snowpack Sensitivity to Temperature and Atmospheric Moisture Changes in Yosemite National Park, CA. JAWRA Journal of the American Water Resources Association, 54(3), 724-741.

Schirmer, M, \& Lehning, M. 2011. Persistence in intra-annual snow depth distribution: 2. Fractal analysis of snow depth development. Water Resources Research, $47(9)$.

Schirmer, M, Wirz, V, Clifton, A, \& Lehning, M. 2011. Persistence in intra-annual snow depth distribution: 1. Measurements and topographic control. Water Resources Research, $\mathbf{4 7}(9)$.

Stewart, Iris T, Cayan, Daniel R, \& Dettinger, Michael D. 2004. Changes in snowmelt runoff timing in western North America under abusiness as usual'climate change scenario. Climatic Change, 62(1-3), 217-232. 
Sturm, Matthew, \& Wagner, Anna M. 2010. Using repeated patterns in snow distribution modeling: An Arctic example. Water Resources Research, 46(12).

Sturm, Matthew, Goldstein, Michael A, \& Parr, Charles. 2017. Water and life from snow: A trillion dollar science question. Water Resources Research, 53(5), 35343544.

Susong, David, Marks, Danny, \& Garen, David. 1999. Methods for developing time-series climate surfaces to drive topographically distributed energy-and waterbalance models. Hydrological Processes, 13(12-13), 2003-2021.

Tennant, Christopher J, Harpold, Adrian A, Lohse, Kathleen Ann, Godsey, Sarah E, Crosby, Benjamin T, Larsen, Laurel G, Brooks, Paul D, Van Kirk, Robert W, \& Glenn, Nancy F. 2017. Regional sensitivities of seasonal snowpack to elevation, aspect, and vegetation cover in western North America. Water Resources Research, 53(8), 6908-6926.

Tinkham, Wade T, Smith, Alistair MS, Marshall, Hans-Peter, Link, Timothy E, Falkowski, Michael J, \& Winstral, Adam H. 2014. Quantifying spatial distribution of snow depth errors from LiDAR using Random Forest. Remote sensing of environment, 141, 105-115.

Trujillo, Ernesto, Ramírez, Jorge A, \& Elder, Kelly J. 2007. Topographic, meteorologic, and canopy controls on the scaling characteristics of the spatial distribution of snow depth fields. Water Resources Research, 43(7).

Trujillo, Ernesto, Ramírez, Jorge A, \& Elder, Kelly J. 2009. Scaling properties and 
spatial organization of snow depth fields in sub-alpine forest and alpine tundra. Hydrological Processes: An International Journal, 23(11), 1575-1590.

Winstral, Adam, \& Marks, Danny. 2002. Simulating wind fields and snow redistribution using terrain-based parameters to model snow accumulation and melt over a semi-arid mountain catchment. Hydrological Processes, 16(18), 3585-3603.

Winstral, Adam, \& Marks, Danny. 2014. Long-term snow distribution observations in a mountain catchment: Assessing variability, time stability, and the representativeness of an index site. Water Resources Research, 50(1), 293-305.

Winstral, Adam, Marks, Danny, \& Gurney, Robert. 2013. Simulating wind-affected snow accumulations at catchment to basin scales. Advances in Water Resources, 55, 64-79.

Winstral, Adam, Marks, Danny, \& Gurney, Robert. 2014. Assessing the sensitivities of a distributed snow model to forcing data resolution. Journal of Hydrometeorology, 15(4), 1366-1383.

Ye, Hengchun, Yang, Daqing, \& Robinson, David. 2008. Winter rain on snow and its association with air temperature in northern Eurasia. Hydrological Processes: An International Journal, 22(15), 2728-2736.

Zhang, Ziran, Glaser, Steven, Bales, Roger, Conklin, Martha, Rice, Robert, \& Marks, Danny. 2017. Insights into mountain precipitation and snowpack from a basin-scale wireless-sensor network. Water Resources Research, 53(8), 6626-6641. 


\section{APPENDIX A:}

\section{KERNEL SIZE EVALUATION FOR LOCAL MEAN ANALYSIS}


The kernel size has an effect on the result of the residual snow depth values. This is due to the edge effect created from the convolution as the averaging window changes sizes. The snow depth patterns found in the residual snow depth values have an enhanced edge effect as the filter size increases. This is noticeable when looking at the differences between the meadow and canopy boundary. As the filter size increases (i.e. area of mean local snow depth) it incorporates more of the boundary area for the convolution.

This needs to be further investigate as to what filter size creates a good local mean, but doesn't lead to misrepresentation the snow depth processes. For example, the 500-m kernel shows that snow is deeper at the meadow's edge and then becomes shallow directly under the canopy cover.

The 150-m was selected for the main manuscript because it was between the correlation length of a flat meadow area in Tuolumne (variogram analysis by (Currier \& Lundquist, 2018) and that of a spaceborne remote sensing platform (e.g. MODIS). 
Inter-annual

1 ALS/yr. nearest peak SWE

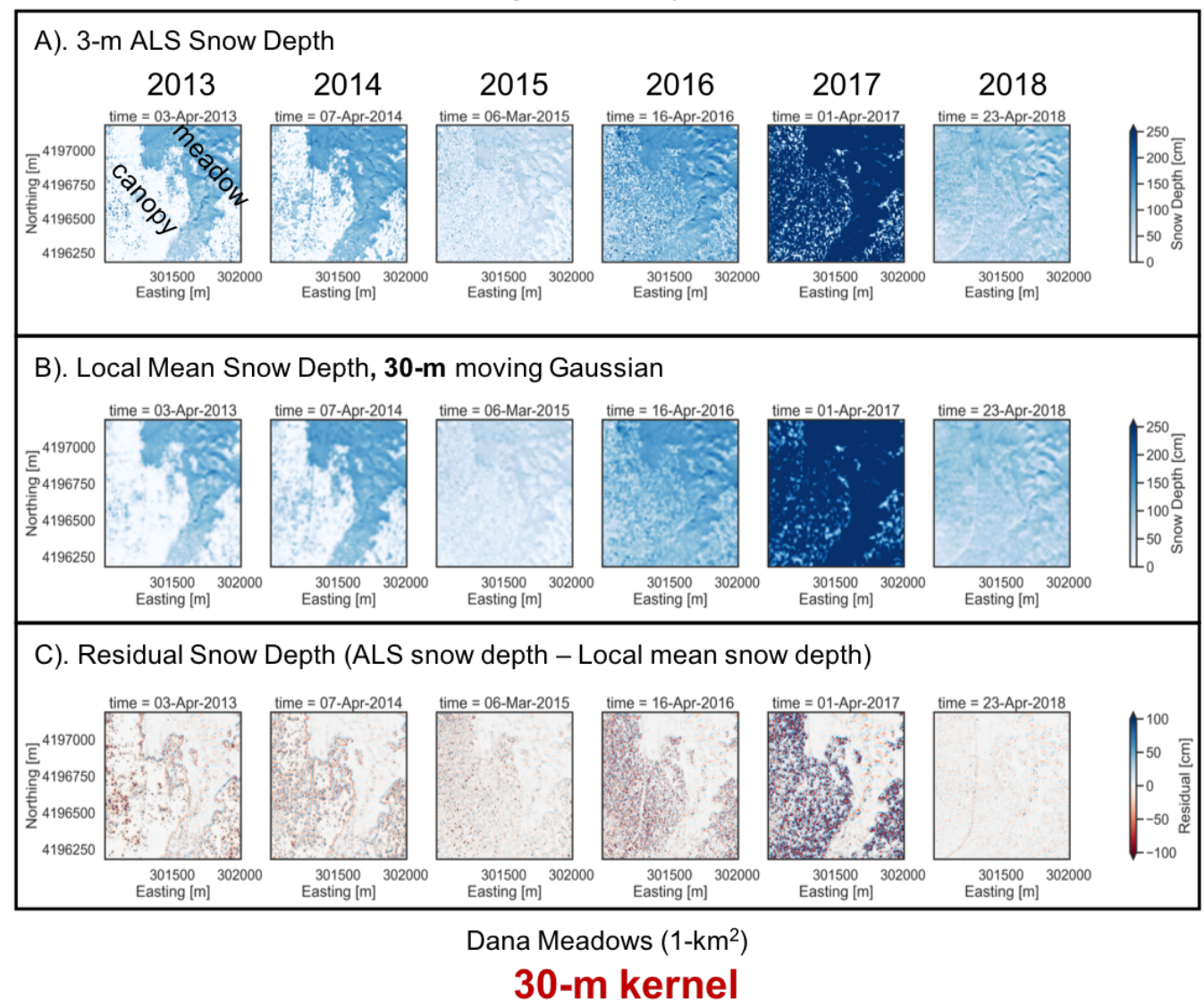

Figure A.1: Local mean analysis evaluated with a 30-m Gaussian kernel 
Inter-annual

1 ALS/yr. nearest peak SWE

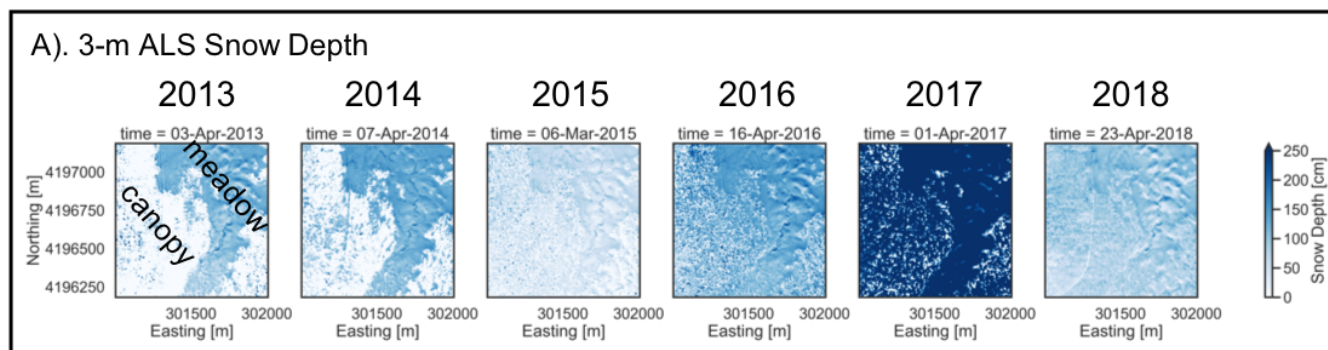

B). Local Mean Snow Depth, 150-m moving Gaussian

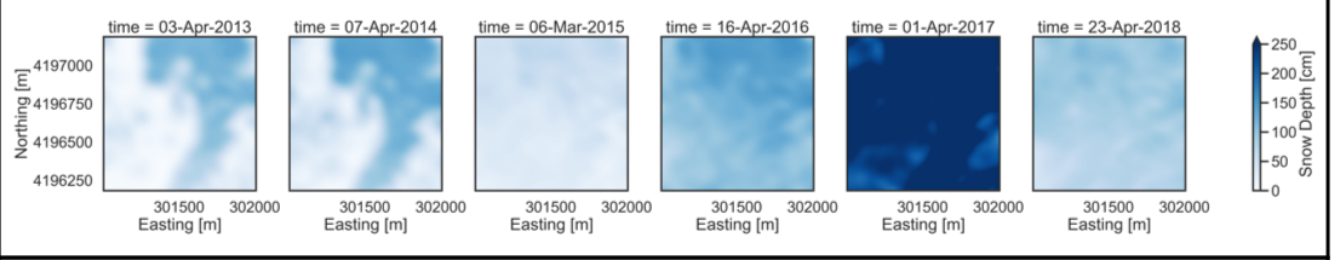

C). Residual Snow Depth (ALS snow depth - Local mean snow depth)

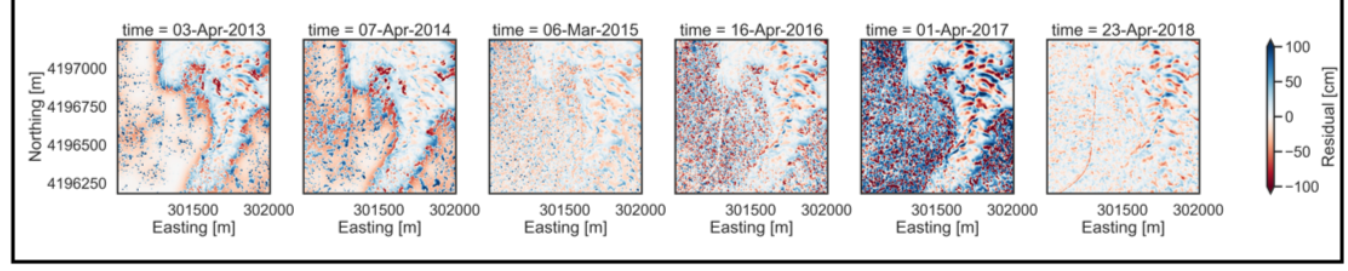

Dana Meadows (1-km²)

150-m kernel

Figure A.2: Local mean analysis evaluated with a 150-m Gaussian kernel 
Inter-annual

1 ALS/yr. nearest peak SWE

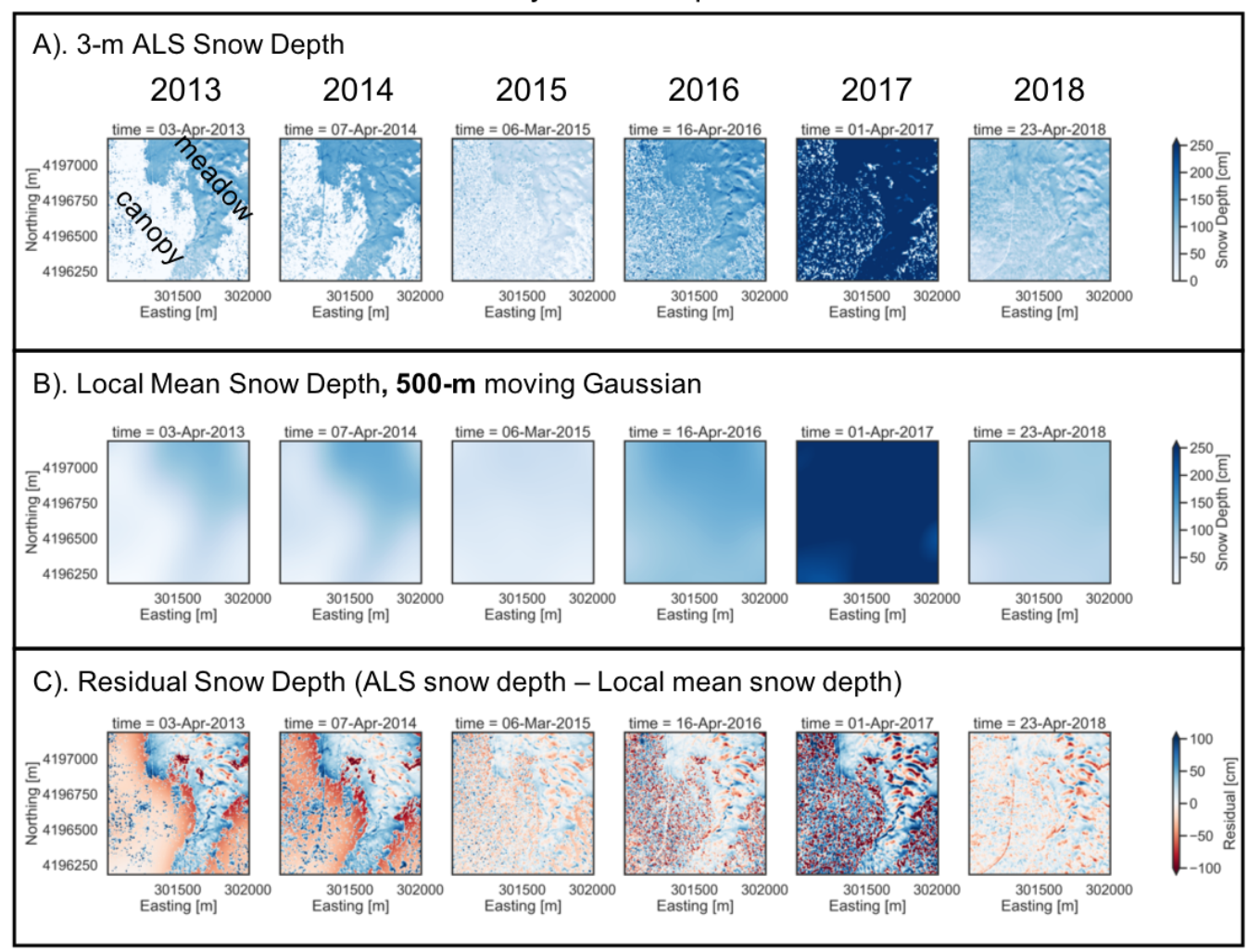

Dana Meadows $\left(1-\mathrm{km}^{2}\right)$

500-m kernel

Figure A.3: Local mean analysis evaluated with a 500-m Gaussian kernel 